\title{
Insolvência empresarial: um estudo sobre as distribuidoras de energia elétrica brasileiras
}

\author{
Corporate insolvency: a study on the brazilian electricity distributors companies
}

Insolvencia empresarial: un estudio sobre las distribuidoras eléctricas brasileñas

\section{Rodrigo Simonassi Scalzer}

Doutorando em Administração pelo Instituto COPPEAD/UFRJ

Professor do Departamento de Ciências Contábeis da Universidade Federal do Espírito Santo Endereço: Avenida Fernando Ferrari, n 514, Bairro Goiabeiras

CEP: 29075-910 - Vitória/ES - Brasil

E-mail: rodrigoscalzer@gmail.com

Telefone: + 55 (27) 3145-5317

\section{Adriano Rodrigues}

Doutor em Controladoria e Contabilidade pela Universidade de São Paulo

Professor do Doutorado em Administração do Instituto COPPEAD/UFRJ

Endereço: Rua Pascoal Lemme, n 355, Ilha do Fundão

CEP: 21941-918 - Rio de Janeiro/RJ - Brasil

E-mail: adriano.rodrigues@coppead.ufrj.br

Telefone: + 55 (21) 3938-5262

\section{Marcelo Álvaro da Silva Macedo}

Doutor em Engenharia de Produção pela Universidade Federal do Rio de Janeiro com Pós-

Doutorado em Controladoria e Contabilidade pela Universidade de São Paulo

Professor do Programa de Pós-Graduação em Ciências Contábeis da Universidade Federal do

Rio de Janeiro

Endereço: Avenida Pasteur, n 250, FACC/UFRJ - Urca

CEP: 22290-240 - Rio de Janeiro/RJ - Brasil

E-mail: malvaro.facc.ufrj@gmail.com

Telefone: +55 (21) 3938-5262

Artigo recebido em 09/09/2015. Revisado por pares em 28/10/2015. Reformulado em 02/12/2015. Recomendado para publicação em 29/12/2015 por Sandra Rolim Ensslin (Editora Científica). Publicado em 30/03/2016. 


\title{
Resumo
}

O objetivo deste trabalho é descobrir quais são os indicadores financeiros e operacionais mais relevantes para a explicação da insolvência no setor de distribuição de energia elétrica no Brasil. Além da grande relevância do setor para a economia brasileira, recentemente a Agência Nacional de Energia Elétrica emitiu a Nota Técnica $n^{\circ} 353 / 2014$ visando criar mecanismos de acompanhamento constante da sustentabilidade econômico-financeira dessas distribuidoras. Para o estudo, foi utilizada a técnica de regressão logística, e a amostra utilizada foi composta pelas empresas de distribuição de energia que tiveram cadastro na Comissão de Valores Mobiliários, ao menos em algum dos anos entre 1997 e 2014 . Os resultados foram consistentes em mostrar que os indicadores Índice de Cobertura dos Juros, Liquidez Geral e FEC/FEC Regulatório foram relevantes para explicar a insolvência das empresas respectivamente para dois anos antes, um ano antes, e para o mesmo ano da análise.

Palavras-chave: Insolvência. Distribuidoras de energia. ANEEL.

\begin{abstract}
The aim of this study is to discover what was the most important financial and operating indicators for the insolvency explanation in the electricity distribution sector in Brazil. Besides the great importance of the sector to the Brazilian economy, recently National Electricity Agency issued Technical Note 353/2014 in order to create constant monitoring mechanisms for the economic and financial sustainability of these distributors. For the study, the logistic regression was used, and the sample was made up of the electricity distribution companies who had joined the Brazilian Securities Commission, in at least one of the years between 1997 and 2014. The results were consistent in showing that interest coverage ratio, overall liquidity, and FEC/FEC Regulatory were relevant to explain the insolvency respectively for two years before, a year earlier, and for the same year analysis.
\end{abstract}

Keywords: Insolvency. Electricity distributors. ANEEL.

\section{Resumen}

El objetivo de este estudio fue descubrir cuáles fueron los más importantes indicadores financieros y operativos para la explicación de la insolvencia en el sector de la distribución de electricidad en Brasil. Además de la gran importancia del sector para la economía brasileña, recientemente la Agencia Nacional de Energía Eléctrica emitió la Nota Técnica 353/2014 a fin de crear mecanismos de vigilancia constantes de la sostenibilidad económica y financiera de estos distribuidores. Para el estudio, se utilizó la regresión logística, y la muestra se compone de las empresas de distribución de electricidad que se habían unido a la Comisión de Valores Mobiliarios, al menos en alguno de los años entre 1997 y 2014. Los resultados fueron consistentes en mostrar que el indicador de cobertura de intereses, la Liquidez Global, y FEC / FEC Regulador eran relevantes para explicar la insolvencia de empresas respectivamente durante dos años antes, un año antes, y para el mismo año.

Palabras clave: Insolvencia. Distribuidoras de electricidad. ANEEL.

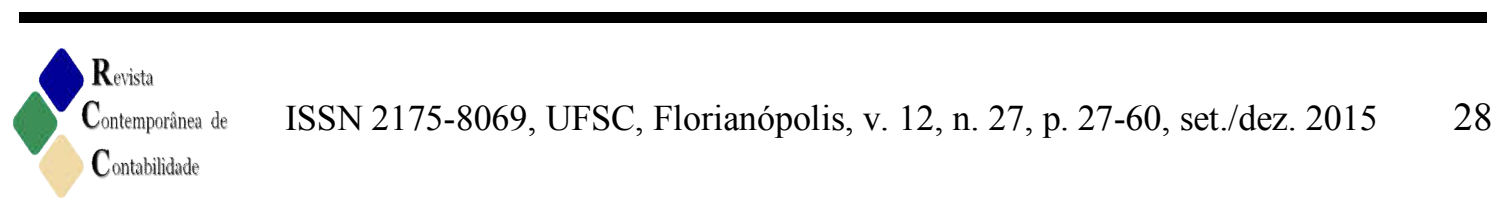




\section{Introdução}

A previsão da insolvência empresarial vem sendo objeto de muitos estudos, por muitos pesquisadores ao redor do mundo, há mais de 45 anos (JACKSON; WOOD, 2013). Conforme destacado por Aziz e Dar (2006), muitos trabalhos têm se dedicado a testar diversos modelos e técnicas estatísticas diferentes com o objetivo de melhor explicar os fatores que podem impactar a sustentabilidade financeira das empresas ao longo do tempo.

Dentre os diversos trabalhos existentes já bastante conhecidos na literatura, os de Beaver (1966) e Altman (1968) desempenharam papel fundamental na construção desse campo de pesquisa. Beaver (1966) propôs a utilização de um modelo univariado de indicadores financeiros para previsão da insolvência empresarial, que propunha um modelo de classificação dicotômica das empresas (solventes e não solventes), utilizando um conjunto de indicadores financeiros e um determinado valor de corte para as informações associadas a cada um desses indicadores. Altman (1968) foi o primeiro trabalho a utilizar a análise discriminante como técnica multivariada que buscava explicar a insolvência empresarial por meio de variáveis explicativas simultaneamente. As variáveis explicativas utilizadas eram indicadores financeiros baseados em números contábeis. Portanto, a relevância da informação contábil já destacada por trabalhos seminais na literatura contábil (BALL; BROWN, 1968; WATTS, 1990; WATTS; ZIMMERMAN, 1978) desempenha papel fundamental na pesquisa de insolvência com a utilização de indicadores que se baseiam em números contábeis.

Pensando em buscar o aperfeiçoamento de suas atividades na regulação do setor elétrico, a Agência Nacional de Energia Elétrica (ANEEL) abriu recentemente a Consulta Pública 05/2014, fruto das discussões presentes na Nota Técnica $n^{\circ} 353 / 2014$, com o objetivo de receber sugestões para criar processos regulatórios de acompanhamento da sustentabilidade financeira e operacional das distribuidoras de energia elétrica. A exemplo do que ocorre com outras agências reguladoras que já possuem procedimentos de acompanhamento da performance das empresas reguladas dos seus respectivos setores de atuação, a ANEEL busca implantar esse acompanhamento também no setor elétrico. Apesar das dificuldades econômico-financeiras encontradas por várias distribuidoras de energia brasileira ao longo dos últimos anos (SILVA, 2011), não há ainda, por parte da ANEEL, uma forma estabelecida para o acompanhamento financeiro e operacional dessas distribuidoras (ANEEL, 2014).

Vale ressaltar que o setor elétrico brasileiro convive com as incertezas historicamente geradas pelas interferências do governo, como ocorreram na época das privatizações e do racionamento de energia dos governos do presidente Fernando Henrique Cardoso (LANDI, 2006), e mais recentemente com a promulgação da Medida Provisória 579/2012 no governo Dilma (COSTELLINI; HOLLANDA, 2014). Em todos esses momentos históricos, várias distribuidoras de energia enfrentaram problemas econômico-financeiros.

Diante do exposto e da relevância do tema abordado, o objetivo deste trabalho é responder à seguinte pergunta de pesquisa: Quais são as variáveis financeiras e operacionais mais relevantes para a explicação da situação de insolvência das distribuidoras de energia elétrica brasileiras?

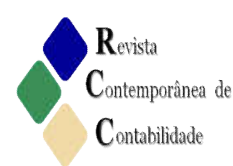


Dessa forma, o presente estudo tem como objetivo descobrir quais são os indicadores financeiros e operacionais que poderiam levar à explicação da situação de insolvência das distribuidoras de energia elétrica no Brasil e, consequentemente, averiguar se existem características que, além de serem comuns entre as empresas insolventes, são diferentes em relação às empresas solventes.

Espera-se que os resultados deste trabalho contribuam com o regulador do setor, a ANEEL, no seu objetivo de estabelecer um conjunto de indicadores para acompanhamento sistematizado da performance financeira e operacional das distribuidoras de energia elétrica. Além disso, espera-se que esse trabalho também apresente resultados que contribuam com as definições de políticas do governo, que historicamente influenciam o setor elétrico por meio de suas intervenções (CATAPAN, 2005). Não obstante, as distribuidoras seriam uma das partes mais interessadas, devido ao estudo tratar propriamente do tipo de negócio delas, e também por estarem interessadas em participar das discussões com a ANEEL.

Fora isso, o setor elétrico é um dos mais importantes da economia brasileira, considerando as necessidades associadas ao seu bom funcionamento e da boa prestação do serviço de fornecimento de energia, bem como devido ao tamanho das empresas contidas nesse setor da economia (LANDI, 2006).

\section{A Pesquisa em Insolvência Empresarial}

A previsão da insolvência empresarial há bastante tempo vem sendo objeto de muitas pesquisas, dado o nível de importância e os impactos que esse tipo de evento gera em todos os stakeholders associados à empresa (BALCAEN; OOGHE, 2006). Assim, a pesquisa, com finalidade em buscar os melhores métodos para previsão de insolvência, já incorpora um histórico de mais de 45 anos de existência, se for considerado que o seu início tenha se dado com o trabalho inovador de Beaver (1966).

Um dos conceitos fundamentais associados a pesquisas de previsão de insolvência é a definição propriamente dita do que seria a própria insolvência. Para Dimitras et al. (1996), a definição de insolvência depende basicamente dos interesses específicos do pesquisador ou das condições das firmas que estiverem sob análise. De uma forma geral, insolvência poderia ser definida como a situação em que a empresa não pode pagar os credores, acionistas minoritários, fornecedores, etc., ou alternativamente também poderia ser definida conforme legislações jurídicas. Para Beaver (1966), insolvência poderia ser definida como a incapacidade da empresa de honrar seus compromissos financeiros conforme eles vão chegando em sua maturidade.

Essa diferenciação quanto aos possíveis critérios para definição de insolvência permeia a literatura acadêmica em trabalhos recentes (JACKSON; WOOD, 2013; BALCAEN et al., 2011; SOARES; REBOUÇAS, 2014). Balcaen et al. (2011) buscaram aprofundar o estudo da insolvência, tentando diferenciar os diversos "estados de insolvência", discriminando-os entre os conceitos de falência, liquidação voluntária e fusões e aquisições. No estudo, foram levantadas evidências de que a liquidação voluntária e a falência resultam

\footnotetext{
Rerista

Contemporanea de ISSN 2175-8069, UFSC, Florianópolis, v. 12, n. 27, p. 27-60, set./dez. 2015 
de caminhos diferentes entre as empresas que se encontram nessas condições. Esse resultado estava em acordo com o trabalho de Balcaen et al. (2009) que encontraram evidências de vários fatores que explicavam de forma diferente as liquidações voluntárias das liquidações involuntárias.

Dentro dessa linha de pesquisa, a relevância e a qualidade da informação contábil sempre foram destacadas como tendo papel fundamental, uma vez que elas são a fonte originária das informações utilizadas pelos indicadores financeiros (ALTMAN, 1968; BALCAEN; OOGHE, 2006; BALL; BROWN, 1968; BEAVER, 1966; DIMITRAS et al., 1996; WATTS, 1990; WATTS; ZIMMERMAN, 1978). Em um dos trabalhos pioneiros na utilização de indicadores financeiros para previsão de insolvência empresarial, Beaver (1966) destacou que possivelmente a maior contribuição daquele trabalho era demonstrar que a utilidade da informação contábil consistia em sua capacidade de predição.

A utilização de indicadores financeiros para a previsão e explicação da insolvência remonta a uma abrangente literatura com trabalhos já publicados sobre o tema que ainda é bastante discutido nos tempos atuais e em diversos países. É possível encontra pesquisadores com estudos, publicados em periódicos de referência, que fazem análises com dados de países, como Romênia (MARICICA; GEORGETA, 2012), Taiwan (LIN et al.,2011) e Turquia (DELEN et al., 2013). Alternativamente, alguns outros trabalhos se dedicam a tentar melhorar os critérios metodológicos dos modelos de insolvência, por meio de critérios de escolha dos indicadores financeiros. Esse é o caso de Niemann et al. (2008), que buscaram reduzir a heterogeneidade dentro dos grupos de classificação de empresas solventes e insolventes para melhorar a capacidade de previsão dos modelos. Outro exemplo seria o trabalho de Wang e Lee (2008) que propôs um método de agrupamento dos indicadores financeiros para posterior seleção e inclusão nos modelos. Por sua vez, Obermann e Waack (2015) demonstraram que a utilização de árvores de decisão simples poderiam ser tão eficientes na previsão de insolvência quanto à utilização de outros modelos mais complexos.

Historicamente, os primeiros trabalhos que utilizaram indicadores financeiros para tentar prever insolvência empresarial foram feitos utilizando modelos univariados. A exemplo de Beaver (1966), Mears (1966) e Neter (1966), os modelos univariados de previsão de insolvência fazem várias comparações de indicadores relevantes da empresa com os indicadores do setor de atuação dessa mesma empresa.

Posteriormente, em resposta à utilização dos modelos univariados, conforme destacado por Balcaen e Ooghe (2006), surgiram trabalhos como o de Tamari (1966) com o objetivo de elaborar uma pontuação qualitativa de índices financeiros, que conseguisse prever, com base na pontuação de cada empresa, aquelas que teriam maiores chances de se tornarem insolventes.

Após o trabalho precursor de Beaver (1966), outros trabalhos também surgiram na mesma época, com grande utilização metodológica até os dias de hoje. Talvez o principal deles tenha sido o inovador trabalho elaborado por Altman (1968). Esses dois trabalhos provavelmente foram os mais influentes para a literatura de previsão de insolvência, uma vez que as metodologias apresentadas por ambos foram e continuam sendo bastante utilizadas em

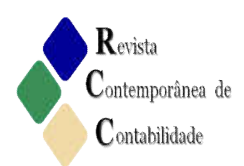


muitos países e com aplicações diversas em vários tipos de setores industriais (ALTMAN, 1984).

Beaver (1966) testou 14 indicadores financeiros e encontrou que o indicador fluxo de caixa sobre a dívida total era o melhor classificador para previsão de insolvência empresarial dentre todos os outros indicadores analisados. Tal resultado possui evidências de sua eficácia em trabalhos até hoje (JACKSON; WOOD, 2013). Por sua vez, o trabalho de Altman (1968) foi o primeiro que apresentou um modelo de análise discriminante para previsão de insolvência das empresas e que utilizou diversas variáveis combinadas simultaneamente. Posteriormente, o modelo de Altman (1968), que até então havia se tornado bastante difundido e muito utilizado tanto no mercado, quanto na literatura acadêmica, foi melhorado e mais bem desenvolvido por meio do modelo Zeta (ALTMAN et al., 1977). Este último também era um modelo de análise discriminante que buscava prever a insolvência das empresas com até cinco anos de antecedência.

Após os trabalhos de Beaver (1966) e de Altman (1968), houve, durante a década de 1970, uma grande quantidade de publicações que utilizavam a análise discriminante na previsão de insolvência (JACKSON; WOOD, 2013) e que, depois de receberem muitas críticas ao não atendimento dos pressupostos metodológicos dessa técnica, culminaram no desenvolvimento de uma grande quantidade de trabalhos que utilizavam a regressão logística, influenciados principalmente pelo trabalho de Ohlson (1980). A partir daí, com os avanços tecnológicos da década de 1990, surgiram uma variedade de metodologias computacionais em trabalhos para previsão de insolvência como redes neurais, testes recursivos, utilização de algoritmos, dentre outras inúmeras técnicas alternativas (DIMITRAS et al., 1996).

De todas as técnicas estatísticas utilizadas na previsão de insolvência, as mais utilizadas amplamente na literatura são os modelos univariados, modelos de análise discriminante e modelos de probabilidade condicinal como logit, probit e modelos de probabilidade linear (BALCAEN; OOGHE, 2006; OHLSON, 1980). De acordo com Altman e Saunders (1997), pelo menos em termos de publicações no Journal of Banking \& Finance, os modelo de análise discriminante e de regressão logística são de longe os tipos mais utilizados. Conforme Aziz e Dar (2006), em trabalho feito por meio de uma revisão de literatura sobre estudos de previsão de insolvência, detectou-se que 51,6\% dos trabalhos analisados utilizaram análise discriminante ou modelos logit.

$\mathrm{Na}$ área bancária, em virtude das exigências dos acordos de Basileia, uma vasta literatura também se desenvolveu com enfoque mais voltado para a análise do risco de crédito. Conforme Crouhy et al. (2000), muitos modelos matemáticos sofisticados foram desenvolvidos, como são os casos do CreditMetrics, proposto pelo JP Morgan; o RiskCalc da Moodys; e o CreditRisk+ do Credit Suisse. Também Gordy (2000) e Lopez e Saidenberg (2000) fizeram comparações da anatomia e eficiência desses diferentes tipos de modelos de análise de crédito.

No contexto brasileiro, também existe uma ampla quantidade de trabalhos realizados nessa linha de pesquisa. Em aplicação feita no Brasil, junto com outros pesquisadores brasileiros, Altman et al. (1979) utilizou o modelo Zeta adaptando duas variáveis à realidade do contexto contábil brasileiro. O modelo adotado obteve resultados com forte acurácia de 
previsão da insolvência das empresas brasileiras, demonstrando que os números contábeis brasileiros da época tinham grande capacidade informativa (ALTMAN et al., 1979).

De todos os trabalhos feitos no Brasil, talvez os que receberam mais destaque em termos de replicações em outros trabalhos nacionais subsequentes foram os de Elisabetsky (1976), Kanitz (1978) e Matias (1978). Todos eles utilizaram a análise discriminante como técnica estatística para elaboração do modelo estimado.

Elisabetsky (1976) elaborou um estudo com 373 empresas do setor de confecções, sendo 274 empresas classificadas como tendo boas condições financeiras, e 99 empresas como tendo más condições financeiras. Utilizando um conjunto de 38 indicadores financeiros, foi criado um modelo multilinear final com cinco variáveis eleitas como relevantes para previsão de insolvência: lucro líquido/vendas, disponível/ativo permanente, contas a receber/ativo total, estoque/ativo total e passivo circulante/ativo total. Dentro da mesma linha metodológica, Kanitz (1978) utilizou 5.000 demonstrações financeiras de empresas brasileiras e separou 21 empresas aleatoriamente que haviam falido entre 1972 e 1974. Com um modelo de análise discriminante, também definiram-se cinco variáveis como sendo as mais relevantes na explicação de insolvências das empresas: lucro líquido/patrimônio líquido, (ativo circulante + realizável a longo prazo)/exigível total, (ativo circulante - estoques)/passivo circulante e exigível total/patrimônio líquido.

Matias (1978) utilizou uma amostra de 100 empresas de diversos setores, sendo 50 solventes e 50 insolventes e encontrou que seis variáveis seriam as mais relevantes, sendo elas: patrimônio líquido/ativo total, financiamento e empréstimos bancários/ ativo circulante, fornecedores/ativo total, ativo circulante/passivo circulante, lucro operacional/lucro bruto e finalmente, disponível/ativo total. Com base nesses três trabalhos pioneiros em sua época no Brasil, vários outros surgiram dentro da literatura brasileira, buscando desenvolver modelos de previsão de insolvência. O Quadro 1 apresenta os trabalhos presentes na literatura brasileira sobre o tema.

Pode-se observar, no Quadro 1, que, na maioria das pesquisas brasileiras, foi utilizada a técnica de análise discriminatória. Isso decorre do fato de que muitos trabalhos fazem adaptações ou replicações dos três modelos já abordados de Elisabetsky (1976), Kanitz (1978) e Matias (1976) para amostras diferentes em períodos diferentes. Também se observa que não há um estudo que volte sua atenção para a análise da insolvência das distribuidoras de energia elétrica.

Soares e Rebouças (2014) buscaram avaliar a capacidade preditiva de diferentes técnicas no mercado brasileiro, baseando-se nas técnicas de análise discriminante, regressão logística, árvores de classificação e redes neurais artificiais. Como resultado, foi visto que, embora todas as técnicas tenham apresentado bons resultados, as redes neurais artificiais obtiveram desempenho superior.

No que tange às pesquisas já realizadas com empresas do setor elétrico, alguns trabalhos buscaram avaliar quais fatores poderiam impactar o desempenho financeiro das empresas de energia elétrica. 
Quadro 1 - Literatura brasileira sobre insolvência empresarial

\begin{tabular}{|c|c|c|}
\hline Referência Bibliográfica & Amostra utilizada & Técnica Utilizada \\
\hline Sanvicente e Minardi (1998) & $\begin{array}{l}92 \text { empresas com ações na Bovespa entre } 1986 \text { e } \\
1998 .\end{array}$ & Análise discriminante \\
\hline Mário (2002) & $\begin{array}{l}\text { Empresas Minerais com falência decretada junto às } \\
\text { Varas de Falências e Concordatas de Belo Horizonte, } \\
\text { Betim e Contagem }\end{array}$ & Análise discriminante \\
\hline Martins (2003) & $\begin{array}{l}\text { Empresas concordatárias com capital aberto entre o } \\
\text { período de } 1990 \text { e } 2000 .\end{array}$ & Modelo de Cox (1972) \\
\hline Castro Júnior (2003) & $\begin{array}{l}\text { Empresas não financeiras de capital aberto com dados } \\
\text { de balanço entre } 1996 \text { e } 2002 .\end{array}$ & $\begin{array}{c}\text { Análise discriminante, } \\
\text { regressão logística e redes } \\
\text { neurais }\end{array}$ \\
\hline Pinheiro et al. (2009) & $\begin{array}{l}174 \text { empresas não financeiras com capital aberto na } \\
\text { Bovespa, entre } 1995 \text { e } 2006 .\end{array}$ & Análise discriminante \\
\hline Brito e Assaf Neto (2008) & $\begin{array}{l}66 \text { empresas de capital aberto entre } 1995 \text { e } 2006 \text {, } \\
\text { sendo } 33 \text { empresas em default. }\end{array}$ & Análise Logit \\
\hline Virgilitto e Fama (2008) & $\begin{array}{l}114 \text { empresas da base de dados do SERASA entre os } \\
\text { anos de } 1995 \text { a } 1998 .\end{array}$ & Análise Logit \\
\hline Guimarães e Moreira (2002) & $\begin{array}{l}116 \text { empresas de } 17 \text { setores diferentes, no período de } \\
1994 \text { a } 2003 \text { coletados do banco de dados do SABE } \\
\text { (Sistema de Análise de Balanços de Empresas) do } \\
\text { IBMEC. }\end{array}$ & Análise discriminante \\
\hline Nascimento et al. (2011) & Empresas do setor aéreo: GOL SA e TAM SA & Análise discriminante \\
\hline Carneiro (2011) & $\begin{array}{l}11 \text { concessionárias de transporte com dados financeiros } \\
\text { de } 2006 \text { a 2009, sendo retirados dos relatórios } \\
\text { disponíveis na ANTT (Agencia Nacional de } \\
\text { Transportes Terrestres) }\end{array}$ & Índice $d u$ Pont \\
\hline Silva et al. (2012) & $\begin{array}{l}13 \text { empresas que decretaram falência entre } 1997 \text { e } \\
2003 \text { no mercado brasileiro. }\end{array}$ & Análise discriminante \\
\hline Barros (2013) & $\begin{array}{l}\text { 782, 752, 721, } 763 \text { operadoras de planos de saúde } \\
\text { respectivamente para os anos de 2009, 2010, } 2011 \text { e } \\
\text { 2012. Os dados foram coletados das informações } \\
\text { financeiras disponíveis no site da ANS (Agencia } \\
\text { Nacional de Saúde). }\end{array}$ & Análise discriminante \\
\hline
\end{tabular}

Fonte: Elaborado pelos autores (2015).

Ribeiro et al. (2012) buscaram averiguar quais indicadores financeiros e operacionais impactavam a sustentabilidade financeira das distribuidoras de energia elétrica, utilizando questionários com analistas do Banco Nacional de Desenvolvimento Econômico e Social (BNDES), e percebeu que, nas perspectivas financeira e operacional, os principais indicadores seriam: cobertura de juros, Frequência Equivalente de Interrupção (FEC) e a Duração Equivalente de Interrupção (DEC). Bomfim et al. (2011) analisaram se o desempenho de curto prazo das empresas de energia, medidos pelo Return On Assets (ROA) e Return On

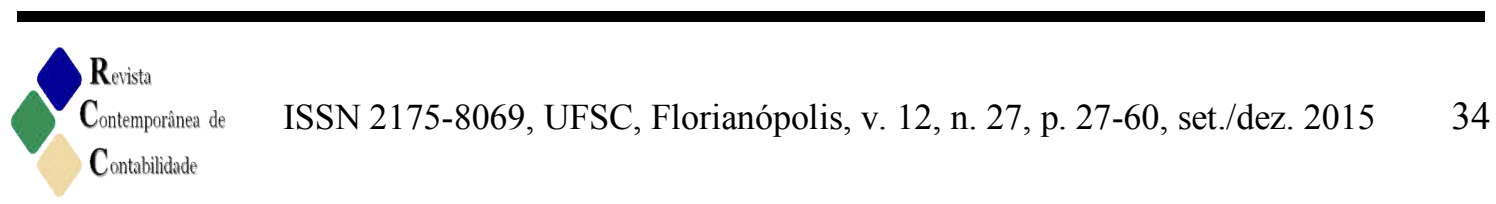


Equity (ROE) eram explicados por fatores definidos sobre um conjunto de indicadores financeiros para dados coletados exclusivamente em 2008. Os autores notaram que os indicadores associados a garantias de pagamento das obrigações com recursos provenientes das operações possuíam poder explicativo sobre o desempenho das distribuidoras. Ozório (2013) fez uma análise do desempenho de cinco distribuidoras entre 2001 e 2011 com a utilização analítica de um conjunto de indicadores financeiros, buscando propor uma metodologia de análise financeira para as distribuidoras de energia elétrica. Pereira et al. (2006) utilizaram as técnicas de análise fatorial e discriminante para estabelecer, entre as empresas do setor energético, quais seriam as solventes e as insolventes, utilizando apenas dados de 2003.

A pequena quantidade de pesquisa realizada sobre a análise do desempenho financeiro das empresas de energia elétrica no Brasil não acompanha a grande relevância que esse setor possui para a sociedade e para a economia do País. Apesar disso, nos últimos anos a ANEEL vem trabalhando para encontrar um modelo de acompanhamento e avaliação do desempenho econômico e operacional das distribuidoras de energia elétrica, visando garantir a sustentabilidade dessas empresas e consequentemente do mercado de energia e da boa prestação dos seus serviços. Não obstante isso, no final de 2014 foi emitida a Consulta Pública 015/2014 com a finalidade de receber opiniões do mercado sobre uma nova implantação de mecanismos para avaliação de sustentabilidade das empresas distribuidoras de energia elétrica. Pelo Anexo 1 da Nota Técnica n. 353/2014, uma proposta inicial de indicadores a serem observados já foi feita pelo órgão regulador, a fim de buscar aprimoramento e posterior implantação.

\section{Fatores Históricos que Influenciaram a Sustentabilidade do Setor Elétrico}

Desde a década de 1990 até hoje, existiam três relevantes momentos que impactaram a sustentabilidade do setor elétrico brasileiro:

(i) a promulgação da Lei Geral das Concessões que criou grande parte do arcabouço regulatório conhecido nos dias de hoje (LANDI, 2006);

(ii) o racionamento de energia elétrica em 2001 (CATAPAN, 2005); e,

(iii) a emissão da Medida Provisória no 579/2012 (COSTELLINI; HOLLANDA, 2014).

Conforme Landi (2006), a estabilização econômica advinda do Plano Real, instituído em 1994 pelo governo de Fernando Henrique Cardoso proporcionou a estruturação das bases para o crescimento econômico do País, inclusive por meio do desenvolvimento de um conjunto de novas regras para reestruturação do setor elétrico. Assim, em 1995 foi promulgada a Lei n. 8.987, conhecida como a Lei Geral das Concessões, que foi de fundamental importância para que fossem estabelecidos os critérios para a concessão de serviços públicos, inclusive os referentes à energia elétrica (GOMES; VIEIRA, 2009). Dentre outros temas, essa Lei foi importante para definições de temas como quando há necessidade

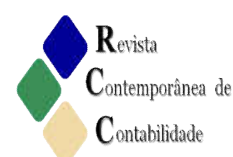


de uma licitação, determinação de prazos para os contratos e o estabelecimento de remuneração do serviço pelo outorgado por meio de uma tarifa que possa ser reajustada ou revisada periodicamente (LANDI, 2006). Conforme destaca Silva (2011), também nessa mesma época ocorreu a desverticalização do setor, que fez com que houvesse a separação das atividades de geração, transmissão, distribuição e comercialização de energia. Até então, as empresas eram todas conhecidas como empresas de ciclo completo, o que dificultava não somente a regulação sobre cada uma das suas atividades de forma independente, como também não favorecia a transparência dessas operações. A partir de então, o setor elétrico começava a ter um formato diferente do que havia até 1994, passando de um setor totalmente estatizado para um setor com prevalência de instituições privadas, onde o Estado passava a exercer um papel preponderante de regulador do mercado.

Com a Lei n. 9.075/95, foi estabelecido o modelo de privatizações que assegurou a execução dos processos de licitação por meio do cancelamento de todas as concessões que fossem vigentes à época e que não tivessem sido submetidas a uma licitação passada. Todo esse processo de mudanças na estrutura do setor elétrico culminou na criação da ANEEL pela promulgação da Lei n. 9.427/96, permitindo que esse órgão passasse a assumir o papel de regulador do setor elétrico a partir dessa data.

Conforme Silva (2011), o processo de privatização das empresas de energia elétrica no Brasil sofreu diversas dificuldades políticas, de forma que diversos congressistas da época se opunham à cessão das empresas estatais para o setor privado. Isso fez com que algumas empresas, como Furnas e Chesf, não fossem privatizadas. Conforme Landi (2006), as privatizações iniciadas em 1995 se deram pelas empresas distribuidoras de energia, uma vez que eram elas as que mais enfrentavam dificuldades financeiras à época, com altos níveis de endividamento.

Todas as alterações, na legislação do setor elétrico dessa época, visavam aumentar a competição e dinâmica do mercado. Contudo, apesar dos grandes esforços nesse sentido, o que se viu nos anos seguintes foi uma averiguação do baixo nível de investimentos por parte dos investidores, principalmente relacionados à geração de energia (CATAPAN, 2005). A iminência de uma crise elétrica no País fez com que o presidente Fernando Henrique instituísse, em 22 de maio de 2001, a Comissão de Análise do Sistema Hidrotérmico de Energia Elétrica, que, dentre outros resultados, culminou na elaboração do relatório que ficou reconhecido como Relatório Kelman. Conforme Landi (2006), uma das principais conclusões apresentadas por esse documento era que a maioria das causas relacionadas à crise do apagão esteve muito mais relacionada às mudanças estruturais implementadas nas reestruturações do setor elétrico brasileiro do que por desequilíbrios conjunturais decorrentes da estiagem vivenciada no fim de 2000 e início de 2001. Conforme também destacado por Catapan (2005), o fato de o marco regulatório ter sido estabelecido somente após o processo de privatização das empresas do setor, fez com que os investidores se sentissem desestimulados para fazer os investimentos que garantissem a expansão do setor, tendo como consequência o racionamento de energia ocorrido em 2001.

O racionamento de energia deflagrado em 2001 no governo de Fernando Henrique gerou consequências financeiras fortes nas empresas elétricas. Após a constatação do apagão

\footnotetext{
$\mathrm{C}_{\text {Contemporânea de }}^{\mathrm{R}_{\text {eista }}}$ ISSN 2175-8069, UFSC, Florianópolis, v. 12, n. 27, p. 27-60, set./dez. 2015
} 
por parte do governo e a consequente criação do programa de racionamento, foi feito, em dezembro de 2001, o chamado "Acordo Geral" do setor elétrico por meio da Lei n. $10.438 / 2002$, que visava ratear os altos custos das contratações emergenciais de energia durante o apagão entre os consumidores finais. Para recompor as perdas impostas às concessionárias durante o racionamento, o governo acrescentou estes cinco encargos adicionais que vigoraram entre $1^{\circ}$ de março de 2002 até 31 de dezembro de 2005: recomposição tarifária extraordinária, encargo de capacidade emergencial, encargo de aquisição de energia elétrica emergencial, encargo de energia livre adquirida no Mercado Atacadista de Energia (MAE) e ressarcimento de acréscimos de custos "não gerenciais" entre $1^{\circ}$ de janeiro e 25 de outubro de 2001.

Além disso, o BNDES também teve uma atuação relevante ao financiar as distribuidoras de energia por meio do Programa de Apoio Emergencial e Excepcional às Concessionárias de Serviços Públicos de Distribuição de Energia Elétrica. Esse financiamento tinha como objetivo ressarcir as distribuidoras das perdas que haviam incorrido com a aquisição antecipada de energia durante o período de racionamento. Em troca do financiamento, as distribuidoras elevaram as tarifas de energia em 2,9\% para consumidores rurais e urbanos (exceto os de baixa renda), e em 7,9\% para todos os demais consumidores. $\mathrm{O}$ pagamento do financiamento do BNDES poderia ser diferido conforme o recebimento dessa recomposição tarifária extraordinária (CATAPAN, 2005).

Passados alguns anos, o governo federal voltou a intervir de forma significativa no setor elétrico. Em 2012, por meio da Medida Provisória n. 579, o governo de Dilma Rousseff decidiu reduzir o custo da energia para o consumidor final por meio da redução de encargos setoriais e custos de geração, transmissão e distribuição de energia (RIO BRAVO, 2012). Os impactos financeiros dessa medida foram significantes para os agentes do setor e acabaram criando instabilidade e insegurança jurídica entre as empresas de energia elétrica.

Visando gerar uma redução de $20,2 \%$ em média de redução no preço de energia para os consumidores, o governo federal tinha o objetivo de estimular o crescimento do setor industrial que vinha registrando quedas nessa mesma época (COSTELLINI; HOLLANDA, 2014). Para atingir tal objetivo, foram tomadas basicamente três medidas: desoneração de encargos setoriais, antecipação de renovação de concessões da geração, transmissão e distribuição de energia, firmadas anteriormente a 1995, e aporte de $\mathrm{R} \$ 3,3$ bilhões anuais pela União à Conta de Desenvolvimento Energético (CDE).

Conforme Rio Bravo (2012), 31,5\% dos custos que compõem a tarifa de energia são oriundos da carga tributária exigida pelo governo, 17,1\% são referentes a encargos setoriais e $51,4 \%$ se referem a custos técnico-operacionais. Apesar disso, a proposta de redução de tarifa por meio da MP 579 do governo envolveu apenas impactos nos encargos setoriais e custos de geração, transmissão e distribuição, permanecendo inalterados os sistemas de arrecadação tributária impostas ao setor. Conforme destacado por Costellini e Hollanda (2014), a redução nos encargos setoriais impactou o valor da tarifa com uma redução média de 7\%. Apesar disso, a MP 579 buscava uma economia adicional de $13,20 \%$ da tarifa pela proposta de renovação das concessões cujos vencimentos ocorreriam a partir de 2015 até 2017. Tais contratos de concessão, que representavam $34 \%$ da energia contratada pelas distribuidoras no

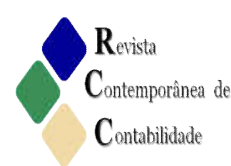


mercado regulado, seriam automaticamente renovados com a antecipação do novo contrato vigorando já para 2012. Para que a renovação acontecesse, as concessionárias precisariam aceitar a indenização dos ativos de concessão ainda não totalmente depreciados ou amortizados pelo valor a ser definido pela ANEEL e, além disso, concordarem com a nova metodologia de cálculo das suas receitas que iriam excluir esses ativos como base para sua remuneração.

Com essa proposta, apenas $60 \%$ da energia prevista inicialmente pelo governo teve seus contratos de concessão renovados e, com isso, muitas distribuidoras que já tinham contratação de energia definida para 2013 acabaram ficando descontratadas em um curto espaço de tempo. Isso fez com que muitas distribuidoras acabassem ficando descobertas em sua contratação, precisando recorrer ao mercado livre ou ao mercado de curto prazo. Ocorre que, junto com essa situação, houve uma forte estiagem fazendo com que os despachos das térmicas aumentassem fortemente os preços da energia no mercado à vista e no mercado livre.

Toda essa situação acabou gerando fortes problemas de caixa para as distribuidoras que, a partir de então, passaram a necessitar de aportes do governo federal, seja para suprir os custos da alta energia de curto prazo, seja também para os efeitos da não redução de energia em decorrência dos contratos não renovados pelas concessionárias que não aceitaram o acordo proposto pela MP 579. Conforme Costellini e Hollanda (2014), o governo precisou aportar nas distribuidoras o valor de $\mathrm{R} \$ 5,1$ bilhões para que pudesse garantir a meta inicial de $20,2 \%$ de redução no preço da energia.

Para solucionar os problemas de liquidez de curto prazo das distribuidoras de energia, o governo implementou, dentre outras ações, a entrada, em vigor a partir de 2015, do regime de bandeiras tarifárias que visava aumentar o preço da energia dos consumidores que consomem mais. Além disso, foram anunciados novos leilões de energia que, somados à energia mais barata dos contratos não renovados que vencem entre 2015 e 2017, devem atender melhor às demandas das distribuidoras, reduzindo sua exposição no mercado de curto prazo.

\section{Método}

Esse trabalho busca descobrir quais são as variáveis financeiras e operacionais mais relevantes na explicação da insolvência empresarial das distribuidoras de energia elétrica. Portanto, espera-se que os resultados encontrados sirvam para contribuir com essa lacuna de pesquisa pouco explorada pela literatura referente ao setor elétrico brasileiro. Espera-se ainda que sejam apresentadas contribuições para as demandas recentes com a Consulta Pública 015/2014 da ANEEL que resultou das discussões propostas da Nota Técnica da ANEEL n. $353 / 2014$, que faz uma proposta de modelo para a avaliação da sustentabilidade financeira das distribuidoras brasileiras de energia elétrica.

Para atender ao objetivo desta pesquisa, será utilizada a técnica de regressão logística, que, segundo Hair et al. (2010), é um tipo de regressão especializada em explicar e prever uma variável dependente categórica binária por meio de variáveis independentes que podem

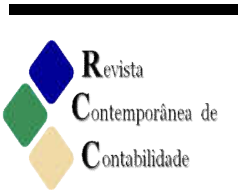


ser métricas ou não métricas. Segundo Fávero et al. (2009), a regressão logística estima os parâmetros pela maximização da verossimilhança e possui a vantagem de não exigir homogeneidade de variância e normalidade dos resíduos, como no caso da regressão múltipla. Junto com isso, optou-se pela análise de regressão logística, uma vez que ela também é uma técnica bastante difundida e utilizada pela literatura de insolvência empresarial (BEAVER et al., 2012; AZIZ; DAR, 2006; JACKSON; WOOD, 2013).

Foram tratados os estados de solvência ou insolvência das empresas como uma variável dicotômica em que se classificou cada uma das empresas em cada ano da análise como sendo participante do grupo de empresas solventes ou do grupo de empresas insolventes. A análise de regressão logística ocorreu da seguinte maneira:

$$
\ln \left(\frac{p_{i}}{1-p_{i}}\right)=\beta_{0}+\beta_{1} x_{1, i}+\cdots+\beta_{k} x_{k, i}
$$

O logit de probabilidade assume a probabilidade de uma determinada distribuidora de energia ser classificada como insolvente $=1$ ou solvente $=0$, em que $p_{i}$ é a probabilidade de ocorrência do evento estudado "estado de insolvência", e $1-p_{i}$ é a probabilidade de não ocorrência do evento. $\beta_{k}$ são os parâmetros associados às variáveis explicativas $x_{k, i}$ que representam cada indicador financeiro e operacional utilizado, para os $k$ indicadores utilizados, e para as $i$ observações utilizadas na amostra. .

Neste estudo, foram realizados testes para verificar como as variáveis explicativas conseguiriam explicar o estado de insolvência para o mesmo ano da ocorrência do evento, um ano antes e dois anos antes. Conforme Dimitras et al. (1996), é comum que, em trabalhos de análise de insolvência empresarial, se utilizem indicadores de anos anteriores para tentar antecipar as causas que levaram à insolvência empresarial. Altman et al. (1977) testou o seu modelo Zeta, criado por ele em 1968, analisando sua capacidade preditiva para até cinco anos anteriores à identificação da insolvência por parte das empresas. Apesar disso, neste estudo não foi possível realizar os testes para mais do que dois anos antes do estado de insolvência devido à limitação de dados uma vez que a amostra utilizada é bastante específica e refere-se ao setor de distribuição de energia elétrica e, por isso, há limitações de disponibilidade quanto às informações mais antigas de alguns dos indicadores utilizados.

As regressões logísticas foram executadas no pacote estatístico $S P S S$ - Versão 22, por meio dos procedimentos stepwise, com a utilização de cutoff padrão de 0,5 para todas as regressões. Posteriormente, foram feitas as análises das áreas abaixo da curva Receiver Operating Characteristic (ROC) das regressões para efeito de análise e comparabilidade da eficiência dos modelos segundo suas sensibilidades e sensitividades (HAIR et al., 2010).

A amostra da pesquisa se baseou em informações dos demonstrativos financeiros, disponíveis publicamente das empresas distribuidoras de energia elétrica, sendo que esse foi o setor escolhido para análise devido à sua relevância para a sociedade (LANDI, 2006) e também em decorrência das recentes demandas apresentadas pela ANEEL por meio da Nota Técnica n. 353/2014 (ANEEL, 2014). Para isso, foram coletados os dados anuais dos demonstrativos financeiros de todas as empresas distribuidoras de energia elétrica que tiveram registro na Comissão de Valores Mobiliários (CVM) em algum momento entre 1997 e 2014.

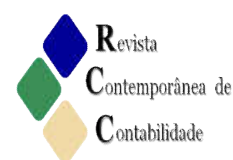


Dessa maneira, buscou-se utilizar a maior amostra possível com informações disponíveis, até mesmo com empresas que não tivessem capital aberto na Bolsa de Valores de São Paulo (BOVESPA), mas que, por algum outro motivo, detinham registro ativo na CVM. O período inicial, a partir de 1997, foi determinado pela disponibilidade de dados no site da CVM, junto com o fato de ter sido esse o primeiro ano a ter números contábeis sem a correção monetária integral de demonstrações financeiras.

Os dados coletados foram baseados nas demonstrações contábeis de 26 empresas distribuidoras de energia elétrica encontradas para o período selecionado, montando um conjunto de 468 observações no período analisado. Para classificar as empresas como distribuidoras de energia elétrica, foi feito o acesso ao relatório de cada uma das empresas individualmente, e coletou-se a informação referente a qual era o objetivo social contido nas notas explicativas. Vale ressaltar que a amostra é composta de empresas exclusivamente distribuidoras, de tal forma que não foram consideradas as empresas integradas, ou seja, as que possuíam conjuntamente mais de uma dentre as atividades de geração, transmissão e distribuição de energia elétrica.

As 26 empresas da amostra foram classificadas como solventes ou insolventes, em cada um dos anos entre 1997 e 2014. As empresas insolventes foram definidas conforme o atendimento de, ao menos, um dos seguintes critérios abaixo, sendo que as demais foram classificadas como sendo solventes:

i) ter apresentado valor do Patrimônio Líquido negativo naquele ano; ou

ii) ter entrado com solicitação de Recuperação Judicial naquele ano; ou

iii) ter recebido Intervenção da ANEEL naquele ano.

As informações para os itens ii) e iii) foram coletadas no site da CVM, na consulta de fatos relevantes emitidos pelas próprias empresas que possuíam cadastro com registro ativo.

O tratamento da insolvência pela identificação do Patrimônio Líquido negativo da empresa é um dos critérios mais amplamente utilizados na literatura para classificar insolvência em um grupo de empresas estudadas (WRUCK, 1990; GUIMARÃES; MOREIRA, 2008; BARROS, 2013). Os trabalhos de Wruck (1990) e Altman (1983) já defendiam que as empresas com insolvência baseada em saldos são as que estão com o valor dos ativos inferiores ao valor dos passivos e, portanto, se encontrariam em situação crônica. Isso faria com que essas empresas não pudessem ser classificadas como estando em insolvência técnica ou temporária.

Dentre as 26 empresas que compuseram a amostra utilizada, oito apresentaram estado de insolvência em algum momento, sendo que, dessas, algumas estiveram em estado de insolvência mais de uma vez, fazendo com que fossem identificados um conjunto de 12 observações em estado de insolvência ao longo de 1997 a 2014, conforme demonstrado no Quadro 2.

Após a definição do grupo das empresas insolventes, foram definidas as empresas solventes que seriam utilizadas como comparáveis às empresas insolventes no modelo de regressão logística. Assim, foi definido inicialmente um grupo de empresas comparáveis na proporção de uma empresa insolvente para uma solvente, e posteriormente um outro grupo de empresas comparáveis na proporção de duas empresas solventes para uma insolvente. A

\footnotetext{
Rerista

Contemporanea de ISSN 2175-8069, UFSC, Florianópolis, v. 12, n. 27, p. 27-60, set./dez. 2015 
definição das empresas comparáveis foi baseada no critério Valor Total dos Ativos do mesmo ano em que a empresa insolvente apresentou seu estado de insolvência (ALTMAN, 1979). Buscou-se assim fazer com que a comparação das empresas solventes com as insolventes fosse realizada entre empresas com características o mais semelhantes possível, sabendo-se que ambas teriam a mesma atividade de distribuição e estariam com o tamanho semelhante segundo o seu valor de seu ativo total.

Quadro 2 - Empresas Insolventes da Amostra

\begin{tabular}{|c|l|c|c|}
\hline Cód. CVM & \multicolumn{1}{|c|}{ Nome da Empresa Insolvente } & $\begin{array}{c}\text { Ano da } \\
\text { Insolvência }\end{array}$ & $\begin{array}{c}\text { Motivo da Classificação } \\
\text { como Insolvente }\end{array}$ \\
\hline 803 & LIGHT SESA & 2001 & Patrimônio Líquido Negativo \\
\hline 1652 & AES SUL DISTRIB. GAÚCHA DE ENERGIA S.A. & 2002 & Patrimônio Líquido Negativo \\
\hline 244 & CELG DISTRIBUIÇÃO S.A. & 2002 & Patrimônio Líquido Negativo \\
\hline 1660 & $\begin{array}{l}\text { COMPANHIA ENERGÉTICA DO MARANHÃO } \\
\text { CEMAR }\end{array}$ & 2002 & $\begin{array}{c}\text { Intervenção da Aneel e } \\
\text { Patrimônio Líquido Negativo }\end{array}$ \\
\hline 1748 & ELEKTRO - ELETRICIDADE E SERVIÇOS S.A. & 2002 & Patrimônio Líquido Negativo \\
\hline 1652 & AES SUL DISTRIB. GAÚCHA DE ENERGIA S.A. & 2003 & Patrimônio Líquido Negativo \\
\hline 1660 & $\begin{array}{l}\text { COMPANHIA ENERGÉTICA DO MARANHÃO } \\
\text { CEMAR }\end{array}$ & 2003 & Patrimônio Líquido Negativo \\
\hline 1652 & AES SUL DISTRIB. GAÚCHA DE ENERGIA S.A. & 2004 & Patrimônio Líquido Negativo \\
\hline 1652 & AES SUL DISTRIB. GAÚCHA DE ENERGIA S.A. & 2005 & Patrimônio Líquido Negativo \\
\hline 1830 & CENTRAIS ELÉTRICAS DO PARÁ S.A - CELPA & 2012 & $\begin{array}{c}\text { Recuperação Judicial e } \\
\text { Intervenção da Aneel }\end{array}$ \\
\hline 557 & EMPRESA ENERGÉTICA DE M.S. S.A. & 2012 & $\begin{array}{c}\text { Recuperação Judicial e } \\
\text { Intervenção da Aneel }\end{array}$ \\
\hline 1460 & CENTRAIS ELETRICAS MATOGROSSENSES SA & 2012 & $\begin{array}{c}\text { Recuperação Judicial e } \\
\text { Intervenção da Aneel }\end{array}$ \\
\hline
\end{tabular}

Fonte: Elaborado pelos autores (2015).

As regressões logísticas foram realizadas utilizando os indicadores do mesmo ano da insolvência, de um ano antes e de dois anos antes. Isso foi feito utilizando-se os dois grupos de empresas comparáveis, ou seja, utilizando-se o grupo com uma única empresa solvente e depois utilizando o grupo com duas empresas solventes.

Os dados foram coletados por meio de informações contidas nas demonstrações financeiras publicadas na CVM e também pelas bases de dados constantes na plataforma ComDinheiro. Os indicadores utilizados no estudo foram divididos em indicadores financeiros e indicadores operacionais, de tal modo a tentar distinguir se o estado de insolvência das empresas originava-se de características relacionadas a fatores financeiros ou operacionais.

Para a amostra utilizada, foram coletados 54 indicadores financeiros e operacionais, conforme a referência bibliográfica apresentada nos Quadro 3 e 4, respectivamente. As fórmulas com os detalhamentos de cálculo de ambos os indicadores financeiros e operacionais encontram-se no Apêndice 1 deste trabalho.

41 ISSN 2175-8069, UFSC, Florianópolis, v. 12, n. 27, p. 27-60, set./dez. 2015

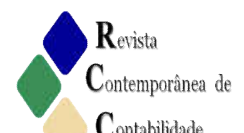


Quadro 3 - Indicadores financeiros utilizados para explicação da insolvência

\begin{tabular}{|c|c|}
\hline Nome do Indicador & Referência base do Indicador \\
\hline Índice de Cobertura dos Juros & Ribeiro et al. (2012), Standard and Poors (2013) \\
\hline $\begin{array}{l}\text { DívidaLíquida/(Ebitda-Capex); Resultado } \\
\text { Financeiro/Ebitda; Capex/Ebitda; Ebit/Imobilizado; } \\
\text { Proventos/Ebitda; Proventos/Lucro Líquido; } \\
\text { Proventos/Capex }\end{array}$ & Nota Técnica Aneel n³53 (2014) \\
\hline Dívida Líquida/ Ebitda & Nota Técnica Aneel n³53 (2014), Standard and Poors (2013) \\
\hline Ebitda/Receita Líquida & Nota Técnica Aneel n³53 (2014), Standard and Poors (2013) \\
\hline Lucro Líquido/Receita Líquida & Nota Técnica Aneel n³53 (2014), Elisabetsky (1976) \\
\hline $\begin{array}{l}\text { Liquidez Geral; Liquidez Seca; Retorno Sobre o } \\
\text { Ativo(ROA); MargemLíquida; Giro do Ativo; Margem } \\
\text { Operacional; LucroOperacional/Despesas Financeiras; } \\
\text { PatrimônioLíquido/Ativo; Endividamento Total; } \\
\text { Endividamento Financeiro/Ativo; Imobilização do } \\
\text { Patrimônio Líquido; FluxodeCaixaOperaciona1/Ativo; } \\
\text { FluxodeCaixaOperacional/Passivo }\end{array}$ & Brito e Assaf Neto (2008) \\
\hline Liquidez Corrente & Brito e Assaf Neto (2008), Matias (1978), Kanitz (1978) \\
\hline Liquidez Imediata & Brito e Assaf Neto (2008), Ribeiro et al. (2012) \\
\hline Retorno sobre o Patrimônio Líquido (ROE) & Brito e Assaf Neto (2008), Kanitz (1978) \\
\hline Lucros Retidos/Ativo & Brito e Assaf Neto (2008), Altman (1979) \\
\hline Patrimônio Líquido/Exigível Total & Brito e Assaf Neto (2008), Sanvicente e Minardi (1998) \\
\hline Estoques/Ativo & Brito e Assaf Neto (2008), Elisabetsky (1976) \\
\hline Capital de Giro Líquido/Ativo & Brito e Assaf Neto (2008), Altman (1979) \\
\hline Fluxo de Caixa Operacional/Endividamento Financeiro & Brito e Assaf Neto (2008), Standard and Poors (2013) \\
\hline $\begin{array}{l}\text { Disponível/ Ativo Permanente; Contas a } \\
\text { Receber/Ativo; Passivo Circulante/Ativo }\end{array}$ & Elisabetsky (1976) \\
\hline Patrimônio Líquido/Ativo & Matias (1978), Altman (1979) \\
\hline $\begin{array}{l}\text { Financiamentos e Empréstimos/Ativo Circulante; } \\
\text { Fornecedores/Ativo; Lucro Operacional/Lucro Bruto; } \\
\text { Disponível sobre o Ativo }\end{array}$ & Matias (1978) \\
\hline $\begin{array}{l}\text { Ativo sobre o Passivo Exigivel; (Ativo Circulante } \\
\text { menos Estoques)/Passivo Circulante; } \\
\text { PassivoExigíve1/Patrimônio Líquido }\end{array}$ & Kanitz (1978) \\
\hline Ebit/Ativo; Receita Líquida/Ativo & Altman (1979) \\
\hline $\begin{array}{l}\text { (Ativo Circulante menos Passivo Exigível)/Ativo; } \\
\text { (Patrimônio Líquido menos Capital Social } \\
\text { Realizado)/Ativo; (Lucro Operacional mais Resultado } \\
\text { Financeiro)/Ativo; Ebit/Despesas Financeiras }\end{array}$ & Sanvicente e Minardi (1998), Standard and Poors (2013) \\
\hline
\end{tabular}

Fonte: Elaborado pelos autores (2015).

A seleção desses indicadores foi fundamentada em referências bibliográficas que possuíam relação com o setor de energia, conforme os trabalhos de Ribeiro et al. (2012), ANEEL (2014) e Standard and Poors (2013).

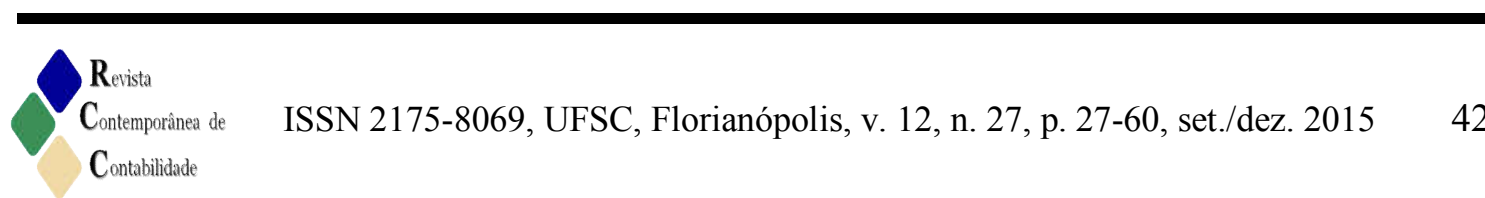


Foram utilizados os indicadores encontrados por Ribeiro et al. (2012), como sendo os mais relevantes para avaliar a sustentabilidade financeira das distribuidoras de energia elétrica. Ribeiro et al. (2012) averiguaram, por meio da técnica Delphi e Análise Hierárquica, junto com questionários feitos para os analistas do BNDES, quais seriam os indicadores financeiros e operacionais mais relevantes para a sustentabilidade das distribuidoras de energia elétrica no Brasil. Já os indicadores utilizados, baseados na ANEEL (2014), foram selecionados conforme os indicadores propostos pelo Anexo 1 da Nota Técnica n. 353/2014, que tem como objetivo propor uma metodologia de regulação do setor para o acompanhamento sistemático da sustentabilidade financeira das distribuidoras de energia elétrica brasileiras (ANEEL, 2014). Nesse caso, foram utilizados os indicadores cujas informações eram públicas e estavam disponíveis entre 1997 e 2014, período de análise adotado por esse estudo.

Os indicadores apresentados no trabalho de Standard and Poors (2013) foram baseados no relatório técnico que apresentava os Principais Fatores de Crédito utilizados para atribuição de rating para as empresas concessionárias de serviços de utilidade pública reguladas pela agência de classificação de risco Standard and Poors.

Os indicadores utilizados, baseados nos trabalhos nacionais de Kanitz (1978), Elisabetsky (1976), Altman (1979), Matias (1978) e Sanvicente e Minardi (1998), foram os indicadores que compuseram os modelos de insolvência encontrados por esses trabalhos, que são referências bastante conhecidas e difundidas na literatura acadêmica brasileira e principalmente na linha de pesquisa sobre insolvência empresarial (SILVA et al., 2012). Além disso, foram utilizados os indicadores adotados por Brito e Assaf Neto (2008) que fizeram uso de uma grande quantidade de indicadores tradicionalmente utilizados na análise financeira de empresas.

Quadro 4 - Indicadores operacionais utilizados para explicação da insolvência

\begin{tabular}{|l|c|}
\hline \multicolumn{1}{|c|}{ Nome do Indicador } & Referência base do Indicador \\
\hline $\begin{array}{l}\text { Duração Equivalente de Interrupção por Unidade } \\
\text { Consumidora (DEC); Frequência Equivalente de } \\
\text { Interrupção por Unidade Consumidora (FEC) }\end{array}$ & Ribeiro et al. (2012) \\
\hline $\begin{array}{l}\text { Duração Equivalente de Interrupção Realizada (DEC)/ } \\
\text { DEC Regulatório; Frequência Equivalente de } \\
\text { Interrupção Realizada (FEC)/FEC Regulatório; } \\
\text { Indicador de Desempenho Global de Continuidade } \\
\text { (IDGC); }\end{array}$ & Nota Técnica Aneel n353 (2014) \\
\hline
\end{tabular}

Fonte: Elaborado pelos autores (2015).

Os indicadores apresentados no Quadro 4 foram classificados como operacionais obedecendo a essa classificação que também foi utilizada tanto no trabalho de Ribeiro et al. (2012), quanto na Nota Técnica n. 353/2014 (ANEEL, 2014). 


\section{Análise da Insolvência das Distribuidoras de Energia}

\subsection{Análise dos Dados Coletados}

Inicialmente, observou-se que alguns indicadores propostos a serem utilizados como variáveis explicativas eram, pelas suas próprias definições, bem parecidos com o Patrimônio Líquido das empresas. Como um dos critérios para a definição da insolvência neste estudo também foi o valor do Patrimônio Líquido como assumindo valor negativo, não haveria sentido tentar utilizar esses indicadores como variáveis explicativas. Dessa maneira, foi utilizado um critério de correlação das variáveis explicativas com o valor do Patrimônio Líquido das empresas para eliminar esse efeito.

Para averiguar qual seria o melhor teste de correlação a ser utilizado, foi realizado o teste de normalidade de Shapiro-Wilk, mais indicado para amostras pequenas, e constatou-se que as distribuições de probabilidade da grande maioria dos indicadores coletados no estudo não seguiam uma distribuição normal. Sendo assim, para o cálculo das correlações procedeuse à utilização do teste não paramétrico de Spearman, mais apropriado para situações com ausência de normalidade na distribuição de probabilidade das variáveis.

Utilizando-se uma correlação de 0,7 positiva ou 0,7 negativa como pontos de corte, foram eliminadas as variáveis apresentadas na Tabela 1. As variáveis eliminadas possuíam forte relação conceitual com o patrimônio líquido, e, além disso, a eliminação dessas variáveis do modelo buscou mitigar o problema de tentar explicar a variável dependente do modelo pr meio dela mesma.

Tabela 1 - Indicadores correlacionados com o critério de insolvência

\begin{tabular}{|c|c|c|c|c|c|c|}
\hline Amostra utilizada & PL/AT & LUCRET./AT & PL/PT & PT/AT & (AC-PT)/AT & (PL-CSR)/AT \\
\hline Insolvência $=\mathrm{PL}<0$ (2 & $\begin{array}{c}\text { Rô Spearman } \\
\text {,901 }^{* *}\end{array}$ & $\begin{array}{c}\text { Rô Spearman } \\
, 826^{* *}\end{array}$ & $\begin{array}{c}\text { Rô Spearman } \\
, 898^{* *}\end{array}$ & $\begin{array}{c}\text { Rô Spearman } \\
-, 905^{* *}\end{array}$ & $\begin{array}{c}\text { Rô Spearman } \\
, 898^{* *}\end{array}$ & $\begin{array}{c}\text { Rô Spearman } \\
{\text {, } 866^{* *}}^{*}\end{array}$ \\
\hline $\mathrm{N}=36)$ & $\begin{array}{c}\text { Sig. (bicaudal) } \\
, 000\end{array}$ & $\begin{array}{c}\text { Sig. (bicaudal) } \\
, 000\end{array}$ & $\begin{array}{c}\text { Sig. (bicaudal) } \\
, 000\end{array}$ & $\begin{array}{c}\text { Sig. (bicaudal) } \\
, 000\end{array}$ & $\begin{array}{c}\text { Sig. (bicaudal) } \\
, 000\end{array}$ & $\begin{array}{c}\text { Sig. (bicaudal) } \\
, 000\end{array}$ \\
\hline Amostra utilizada & PL/AT & LUCRET./AT & PL/PT & PT/AT & (AC-PT)/AT & (PL-CSR)/AT \\
\hline Insolvência $=\mathrm{PL}<0$ & $\begin{array}{c}\text { Rô Spearman } \\
\text {,893 }^{* *}\end{array}$ & $\begin{array}{c}\text { Rô Spearman } \\
, 717^{* *}\end{array}$ & $\begin{array}{c}\text { Rô Spearman } \\
, 876^{* *}\end{array}$ & $\begin{array}{c}\text { Rô Spearman } \\
-, 880^{* *}\end{array}$ & $\begin{array}{c}\text { Rô Spearman } \\
, 826^{* *}\end{array}$ & $\begin{array}{c}\text { Rô Spearman } \\
, 790^{* *}\end{array}$ \\
\hline $\mathrm{N}=36)$ & $\begin{array}{c}\text { Sig. (bicaudal) } \\
, 000\end{array}$ & $\begin{array}{c}\text { Sig. (bicaudal) } \\
, 000\end{array}$ & $\begin{array}{c}\text { Sig. (bicaudal) } \\
, 000\end{array}$ & $\begin{array}{c}\text { Sig. (bicaudal) } \\
, 000\end{array}$ & $\begin{array}{c}\text { Sig. (bicaudal) } \\
, 000\end{array}$ & $\begin{array}{c}\text { Sig. (bicaudal) } \\
, 000\end{array}$ \\
\hline Indicador & \multicolumn{6}{|c|}{ Nome } \\
\hline PL/AT & \multicolumn{6}{|c|}{ Patrimônio Líquido/Ativo } \\
\hline LUCRET./AT & \multicolumn{6}{|c|}{ Lucros Retidos/Ativo } \\
\hline PL/PT & \multicolumn{6}{|c|}{ Patrimônio Líquido/Exigível Total } \\
\hline PT/AT & \multicolumn{6}{|c|}{ Endividamento Total } \\
\hline (AC-PT)/AT & \multicolumn{6}{|c|}{ (Ativo Circulante menos Passivo Exigível)/Ativo } \\
\hline (PL-CSR)/AT & \multicolumn{6}{|c|}{ (Patrimônio Líquido - Capital Social Realizado)/Ativo } \\
\hline
\end{tabular}

\footnotetext{
$R_{\text {evista }}$
$C_{\text {ontemporânea de }}$
Contabilidade ISSN 2175-8069, UFSC, Florianópolis, v. 12, n. 27, p. 27-60, set./dez. 2015
} 
Após ter eliminado as seis variáveis da Tabela 1, a exemplo do que fora feito pelo estudo univariado de Beaver (1966), e também adotado por Brito e Assaf Neto (2008) e Brito et al. (2009), foram realizados os testes para identificação das variáveis que possuíam diferenças entre os grupos insolventes e solventes. Por meio disso, foi possível identificar quais indicadores foram estatisticamente diferentes entre os dois grupos e observar como se comportam no grupo das empresas insolventes.

Para isso, foi utilizado o teste não paramétrico de Mann Whitney, com a utilização do nível de significância a 5\%, que, conforme Fávero et al. (2009), é o mais comumente utilizado em ciências sociais. Os testes foram realizados para os indicadores do mesmo ano do evento da insolvência, para um ano antes e para dois anos antes, tanto para as análises com uma empresa comparada, quanto para as análises com duas empresas comparadas.

Os resultados dos indicadores que apresentaram diferenças significativas entre os grupos para todas as análises realizadas são apresentados no Quadro 5:

Quadro 5 - Indicadores estatisticamente diferentes entre os grupos

\begin{tabular}{|c|c|}
\hline Sigla & Nome do Indicador \\
\hline ICJ & Índice de Cobertura dos Juros \\
\hline DEC & Duração Equivalente de Interrupção por Unidade Consumidorą (DEC) \\
\hline FEC & Frequência Equivalente de Interrupção por Unidade Consumidora (FEC) \\
\hline LG & Liquidez Geral \\
\hline ROA & Retorno sobre o Ativo (ROA) \\
\hline MOP & Margem Operacional \\
\hline LOP/DF & Lucro Operacional/Despesa Financeira \\
\hline DEC/DECREG & Duração Equivalente de Interrupção Realizada (DEC)/ DEC Regulatório \\
\hline FEC/FECREG & Frequência Equivalente de Interrupção Realizada (FEC)/FEC Regulatório \\
\hline IDGC & Indicador de Desempenho Global de Continuidade (IDGC) \\
\hline EBITDA/RL & Ebitda/Receita Líquida \\
\hline LL/RL & Lucro Líquido/Receita Líquida \\
\hline PROV/EBITDA & Proventos/Ebitda \\
\hline PROV/LL & Proventos/Lucro Líquido \\
\hline EBIT/DF & Ebit/Despesas Financeiras \\
\hline
\end{tabular}

Fonte: Elaborado pelos autores (2015).

Os indicadores apresentados no Quadro 5 são aqueles estatisticamente diferentes entre as empresas solventes e insolventes. Em linha com o trabalho precursor de Beaver (1966), com a utilização de testes estatísticos univariados, este resultado consegue demonstrar inicialmente quais variáveis são habitualmente diferentes quando uma empresa de distribuição de energia elétrica está em default, ou até mesmo para as empresas que irão ficar nessa situação dentro do próximo ano ou em até dois anos depois da análise desses indicadores.

Posteriormente, para evitar problemas de multicolinearidade na regressão logística, procedeu-se à eliminação das variáveis com forte correlação entre si. Conforme Wooldridge (2011), a presença de multicolinearidade entre as variáveis faz com que os parâmetros 
estimados na regressão se tornem viesados devido à influência das outras variáveis similares. Portanto, foi feita uma matriz de correlação entre os indicadores que apresentaram diferenças entre os grupos e aplicou-se a eles o teste de correlação não paramétrico de Spearman. Utilizando-se o critério do maior p-valor encontrado no teste de Mann Whitney, aplicado anteriormente na identificação de diferenças entre grupos, eliminou-se o indicador que tivesse forte correlação com algum outro indicador. Para tanto, também se adotou aqui a correlação de 0,7 positiva ou negativa como critério para selecionar os indicadores que tinham alta correlação.

Após terem sido procedidos esses testes, os indicadores restantes, após as eliminações, foram utilizados na realização das regressões logísticas. O Quadro 6 apresenta os indicadores utilizados nos modelos de regressão.

Quadro 6 - Indicadores utilizados na análise de regressão logística

\begin{tabular}{|c|c|}
\hline Sigla & Nome do Indicador \\
\hline DEC & Duração Equivalente de Interrupção por Unidade Consumidorą (DEC) \\
\hline FEC & Frequência Equivalente de Interrupção por Unidade Consumidora (FEC) \\
\hline PF/AT & Endividamento Financeiro/Ativo \\
\hline LG & Liquidez Geral \\
\hline PC/AT & Passivo Circulante/Ativo \\
\hline CT/CP & Endividamento Total \\
\hline ROE & Retorno sobre o Patrimônio Líquido \\
\hline FEC/FECREG & Frequência Equivalente de Interrupção Realizada (FEC)/FEC Regulatório \\
\hline PROV/LL & Proventos/Lucro Líquido \\
\hline LO/LB & Lucro Operacional/Lucro Bruto \\
\hline EBIT/DF & Ebit/Despesas Financeiras \\
\hline
\end{tabular}

Fonte: Elaborado pelos autores (2015).

Os indicadores do Quadro 6 são aqueles que apresentaram diferença entre os grupos em, ao menos, um dos períodos analisados, e após as eliminações realizadas pela análise de multicolinearidade entre os indicadores.

\subsection{Estimação dos modelos}

Para serem feitas as estimações das regressões logísticas, foram utilizados os procedimentos stepwise com inclusão das variáveis a 5\% de nível de significância e com a retirada das variáveis ao nível de significância de $10 \%$, utilizando-se a estatística de Wald que verifica se os parâmetros estimados são estatisticamente diferentes de zero (FÁVERO et al., 2009). Para os procedimentos stepwise, foram utilizados os métodos Razão de Verossimilhança, Wald e Condicional, e, em ambos os casos, os resultados dos modelos foram os mesmos.

\footnotetext{
$R_{\text {evista }}$
$C_{\text {ontemporânea de }}$
Contabilidade ISSN 2175-8069, UFSC, Florianópolis, v. 12, n. 27, p. 27-60, set./dez. 2015
} 
A Tabela 2 apresenta os resultados das estimações dos modelos de insolvência das distribuidoras de energia elétrica para os três períodos em análise, de acordo com o grupo de empresas comparáveis utilizado.

Tabela 2 - Modelos de Insolvência das Distribuidoras de Energia

\begin{tabular}{|c|c|c|c|}
\hline Amostra & Modelo para $t=$ Mesmo Ano & Modelo para $t=1$ anos antes & Modelo para $t=2$ anos antes \\
\hline \multirow{2}{*}{$\begin{array}{c}1 \text { empresa } \\
\text { comparada } \\
(\mathrm{N}=24)\end{array}$} & $\begin{array}{c}\text {-2,997-10,581 LG }+ \\
\text { 14,412FEC/FECREG }\end{array}$ & 4,405 - 7,148 LG & 1,759 - 1,980 ICJ \\
\hline & $\begin{array}{c}\text { Area abaixo da Curva ROC }=96,5 \% \\
\text { Percentual de acerto global }=95,8 \% \\
\text { Pseudo } \mathrm{R}^{2} \text { de Nagelkerke }=81,7 \%\end{array}$ & $\begin{array}{c}\text { Area abaixo da Curva ROC }=87,5 \% \\
\text { Percentual de acerto global }=79,2 \% \\
\text { Pseudo } \mathrm{R}^{2} \text { de Nagelkerke }=48,9 \%\end{array}$ & $\begin{array}{c}\text { Area abaixo da Curva ROC }=86,8 \% \\
\text { Percentual de acerto global }=83,3 \% \\
\text { Pseudo } \mathrm{R}^{2} \text { de Nagelkerke }=54,4 \%\end{array}$ \\
\hline \multirow{2}{*}{$\begin{array}{c}2 \text { empresas } \\
\text { comparadas } \\
(\mathrm{N}=36)\end{array}$} & $\begin{array}{r}-7,767-6,398 \text { LG } \\
+8,950 \mathrm{FEC} / \text { FECREG }\end{array}$ & $3,608+0,24(\mathrm{CT} / \mathrm{CP})-8,132 \mathrm{LG}$ & 0,527 - 1,518 ICJ \\
\hline & $\begin{array}{c}\text { Área abaixo da Curva ROC }=95,1 \% \\
\text { Percentual de acerto global }=97,2 \% \\
\text { Pseudo } \mathrm{R}^{2} \text { de Nagelkerke }=76,8 \%\end{array}$ & $\begin{array}{c}\text { Área abaixo da Curva ROC }=86,1 \% \\
\text { Percentual de acerto global }=94,4 \% \\
\text { Pseudo } \mathrm{R}^{2} \text { de Nagelkerke }=50,6 \%\end{array}$ & $\begin{array}{c}\text { Área abaixo da Curva ROC }=81,8 \% \\
\text { Percentual de acerto global }=66,7 \% \\
\text { Pseudo } \mathrm{R}^{2} \text { de Nagelkerke }=37,9 \%\end{array}$ \\
\hline
\end{tabular}

Fonte: Elaborada pelos Autores (2015).

Pode-se observar pelos resultados, que os modelos previstos apresentaram alta capacidade de explicação e predição da insolvência das empresas distribuidoras de energia, por meio dos resultados apresentados pela área abaixo da curva ROC de cada regressão. A área abaixo da curva ROC mede como os graus de sensitividade e sensibilidade combinados possuem interferência conjunta no percentual de acerto global do modelo, uma vez que, dependendo do cutoff definido pelo pesquisador, pode-se aumentar ou diminuir o acerto da classificação de empresas solventes e insolventes. Atentando-se a isso, para as regressões foi utilizado o cutoff padrão de 0,5 .

A análise dos pseudoR-Quadrados possuem na regressão logística uma interpretação diferente dos R-quadrados analisados nos modelos de regressão tradicionais, devido ao fato de as variáveis dependentes serem categóricas e, portanto, não ser possível analisar quanto da variância da variável dependente deve ser explicada pelas variáveis preditoras (FÁVERO, 2015). Apesar disso, utilizando-se os pseudoR-Quadrados como medidas da qualidade de ajustamento dos modelos, encontrou-se que, para as regressões do mesmo ano do estado de insolvência, o grau de ajustamento foi maior quando comparado com as regressões realizadas para um ano antes e dois anos antes, respectivamente.

Os resultados estimados pelos modelos demonstraram que houve coerência e resultados parecidos entre os modelos com estimações utilizando uma empresa solvente comparada e com duas empresas solventes comparadas, e mostraram que indicadores diferentes detectam a insolvência das distribuidoras dois anos antes, um ano antes e no mesmo ano.

O indicador Índice de Cobertura dos Juros (ICJ), que mede o Lucro antes de Juros, Impostos, Depreciações e Amortizações dividido pelas Despesas Financeiras da empresa, busca medir como as atividades operacionais conseguem cobrir os juros pagos pelas empresas (STANDARD and POORS, 2013; RIBEIRO et al., 2012). Dois anos antes da insolvência, o indicador ICJ foi um importante discriminador entre as empresas solventes e insolventes, apresentando, em todos os casos, parâmetros com sinal positivo, o que faz com que quanto

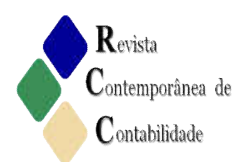


maior for o indicador, maior é a chance de a empresa se tornar insolvente, levando em consideração que as despesas financeiras assumiram valores negativos para os cálculos desse indicador. No caso das distribuidoras de energia, isso demonstra que, dois anos antes da insolvência, as empresas que futuramente estariam insolventes passaram a arcar com valores maiores de juros associados com uma redução em seus lucros operacionais.

Por ser um setor bastante regulado, visando à modicidade tarifária (ANEEL, 2014), as receitas das distribuidoras são definida pelo órgão regulador por meio dos reajustes e das revisões tarifárias e assim necessitam de comprovação e acompanhamento da ANEEL para sua aprovação. Baseados nos critérios de uma empresa de referência, em cada revisão tarifária é feito o cálculo da remuneração do capital próprio e do capital de terceiros da empresa por meio do cálculo do custo médio ponderado de capital. Se eventualmente uma distribuidora assumir um custo com capital de terceiros maior do que o valor que fora definido para o cálculo de sua tarifa, esses custos serão assumidos pela empresa, não podendo ser repassados para o consumidor final, criando assim um fator adicional de dificuldade financeira para as empresas que já estejam nessa situação de alto endividamento.

O indicador Liquidez Geral (LG) mede a liquidez empresarial tanto de curto como de longo prazo, uma vez que é resultante da divisão entre o valor total dos ativos sobre o valor total dos passivos (ASSAF NETO, 2012). Quando se está a um ano do estado de insolvência, o indicador LG passa a ser o mais relevante para distinguir a insolvência, e assim apresenta valor negativo para a estimativa dos parâmetros, de tal forma que quanto maior a Liquidez Geral, menor é a probabilidade de a empresa se tornar insolvente. Isso demonstra que as dificuldades financeiras com os juros do exercício anterior podem acabar gerando diminuição dos ativos totais em decorrência dos altos desembolsos com pagamentos dos valores da dívida e juros, e consequentemente ocorrer o aumento dos passivos pela necessidade de contração de novas dívidas para pagar obrigações de curto prazo.

Por fim, no ano da insolvência das distribuidoras de energia, observa-se que não somente o indicador LG, mas também o indicador FEC/FECREG, que mede a frequência de interrupções no fornecimento de energia por unidade consumidora sobre o nível de frequência de interrupções estabelecidos pela órgão regulador, se apresentou como variável explicativa dos modelos, apresentando sinais positivos nos parâmetros, demonstrando que quanto maior o indicador, maior é a chance de a empresa ser classificada como insolvente. Conforme ANEEL (2014), é importante que se faça o acompanhamento de indicadores operacionais das distribuidoras de energia, uma vez que as concessionárias nem sempre possuem o incentivo de executar o nível de investimento exigido pelo regulador e necessário para o bom fornecimento de serviços à sociedade. A área abaixo da curva ROC e o percentual de acerto global com o cutoff de 0,5 se destacaram ainda mais em relação às regressões dos dois outros períodos temporais anteriores, com a área abaixo da curva ROC atingindo valores maiores do que $95 \%$, e os percentuais de acertos globais atingindo valores maiores do que $95,7 \%$, o que demonstra forte ajustamento e qualidade dos modelos.

Observando os resultados apresentados pelas regressões nos três períodos de tempo, observa-se que foram encontradas evidências de que, para dois anos antes e um ano antes da insolvência, as distribuidoras encontram dificuldades financeiras que posteriormente se

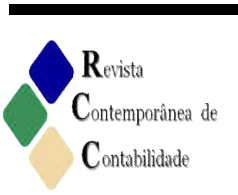

ISSN 2175-8069, UFSC, Florianópolis, v. 12, n. 27, p. 27-60, set./dez. 2015 
traduzem em dificuldades operacionais. Os indicadores presentes nas regressões para dois anos antes e um ano antes foram todos indicadores financeiros, enquanto que, no ano da insolvência, o indicador que mais foi capaz de distinguir características das empresas solventes das empresas insolventes foi um indicador operacional. Tal constatação reafirma a necessidade de a ANEEL se preocupar com o acompanhamento de indicadores operacionais das distribuidoras de energia, conforme consta na proposta apresentada pela Nota Técnica $n$. $353 / 2014$.

\subsection{Análise de robustez dos modelos estimados}

Após terem sido realizadas as regressões logísticas para averiguar quais indicadores melhor explicariam a insolvência das distribuidoras de energia elétrica, foram realizadas novas regressões alterando-se a sensibilidade do critério de insolvência. No que se referia ao Patrimônio Líquido negativo como critério de definição para as empresas insolventes, foi feita a substituição pelo critério Patrimônio Líquido/Ativo $<5 \%$. Buscou-se assim relaxar o critério anteriormente utilizado que, em termos quantitativos, poderia ser tratado como Patrimônio Líquido/Ativo $<0$, uma vez que contabilmente não faz sentido que o Ativo assuma valores negativos.

Com isso, somado às empresas que sofreram recuperação judicial e intervenção da ANEEL que já compunham a amostra anterior, sob o novo critério a amostra passou a conter um conjunto de 21 observações de empresas insolventes, fazendo com que as regressões com uma empresa comparável para cada insolvente contivessem 42 observações, e as que continham duas empresas comparáveis, 63 observações. De posse dessa nova amostra, procedeu-se aos mesmos procedimentos estatísticos realizados com a amostra anterior, referente aos testes de diferenças dos indicadores entre os grupos solventes e insolventes, bem como a retirada das variáveis altamente correlacionadas, até finalmente se chegar à estimação dos modelos de regressão logística para a análise de robustez.

Após proceder com os mesmos passos metodológicos das regressões anteriores, foram encontrados os resultados, conforme demonstrados na Tabela 3.

Tabela 3 - Modelos de insolvência das distribuidoras de energia

\begin{tabular}{|c|c|c|c|}
\hline Amostra & Modelo para $t=$ Mesmo Ano & Modelo para $t=1$ anos antes & Modelo para $t=2$ anos antes \\
\hline \multirow{2}{*}{$\begin{array}{l}1 \text { empresa } \\
\text { comparada } \\
(\mathrm{N}=42)\end{array}$} & $\begin{array}{c}-5,457+15,523 \text { FEC/FECREG } \\
-8,887 \text { LG }\end{array}$ & 4,700 - 1,688 ICJ - 5,583 LG & $\begin{array}{l}1,845 \text { - 2,626 ICJ + } \\
\text { 1,412PROV/EBITDA }\end{array}$ \\
\hline & $\begin{array}{c}\text { Área abaixo da Curva ROC }=96,8 \% \\
\text { Percentual de acerto global }=92,9 \% \\
\text { Pseudo } \mathrm{R}^{2} \text { de Nagelkerke }=81,8 \% \\
\end{array}$ & $\begin{array}{c}\text { Área abaixo da Curva } \mathrm{ROC}=93,4 \% \\
\text { Percentual de acerto global }=89,5 \% \\
\text { Pseudo } \mathrm{R}^{2} \text { de Nagelkerke }=67,6 \% \\
\end{array}$ & $\begin{array}{c}\text { Área abaixo da Curva } \mathrm{ROC}=90,3 \% \\
\text { Percentual de acerto global }=84,2 \% \\
\text { Pseudo } \mathrm{R}^{2} \text { de Nagelkerke }=58,7 \%\end{array}$ \\
\hline \multirow{2}{*}{$\begin{array}{c}2 \text { empresas } \\
\text { comparadas } \\
(\mathrm{N}=63)\end{array}$} & $\begin{array}{c}-7,230-15,043 \text { CCL/AT } \\
+13,409 \text { FEC/FECREG- } 7,245 \text { LG } \\
\end{array}$ & 347 ICJ - 6,281 LG & 723 ICJ \\
\hline & $\begin{array}{c}\text { Área abaixo da Curva ROC }=95,7 \% \\
\text { Percentual de acerto global }=90,5 \% \\
\text { Pseudo } \mathrm{R}^{2} \text { de Nagelkerke }=78,6 \%\end{array}$ & $\begin{array}{c}\text { Área abaixo da Curva } \mathrm{ROC}=91,1 \% \\
\text { Percentual de acerto global }=89,5 \% \\
\text { Pseudo } \mathrm{R}^{2} \text { de Nagelkerke }=57,4 \%\end{array}$ & $\begin{array}{c}\text { Área abaixo da Curva } \mathrm{ROC}=84,4 \% \\
\text { Percentual de acerto global }=77,1 \% \\
\text { Pseudo } \mathrm{R}^{2} \text { de Nagelkerke }=44,0 \%\end{array}$ \\
\hline
\end{tabular}

Fonte: Elaborada pelos autores (2015). 
As variáveis explicativas dos novos modelos apresentados na Tabela 3, realizadas sob o relaxamento do critério de insolvência na variável dependente, apresentaram resultados bastante parecidos, seguindo basicamente a mesma interpretação conceitual anterior dos indicadores nos diferentes períodos. Nas novas regressões apresentadas na Tabela 3, o ICJ que se apresentara nos modelos anteriores apenas dois anos antes, agora também apareceu como variável relevante para os modelos com um ano de antecedência do evento de insolvência. Isso fortalece a percepção de que as empresas que entram em estado de insolvência acabam incorrendo no maior pagamento de juros na forma de despesas financeira junto com dificuldade de produzir lucros operacionais, antes de se tornarem insolventes, gerando assim problemas de liquidez em seus balanços.

Todas as seis novas regressões com análise de robustez das regressões anteriores se demonstraram mais eficientes segundo a área abaixo da curva ROC, e também apresentaram melhor qualidade de ajustamento medidos pelos pseudoR-quadrados. Apenas para fins comparativos, analisando as médias das estatísticas da curva ROC encontradas para uma e duas empresas comparadas da Tabela 2, respectivamente para o mesmo ano, um ano antes e dois anos antes, foram encontrados os valores de $95,8 \%, 86,8 \%$ e $84,3 \%$. Enquanto isso, os valores encontrados para as médias da área abaixo da curva ROC das regressões apresentadas na Tabela 3 foram 96,25\%,92,25\% e 87,35\%. Isso demonstra que os novos modelos se tornaram ainda mais eficientes com o aumento da amostra de empresas insolventes, e consequentemente com o aumento do tamanho dos grupos de empresas comparadas.

\section{Considerações Finais}

Esse trabalho teve como objetivo descobrir quais variáveis financeiras e operacionais explicam a insolvência das distribuidoras de energia elétrica brasileiras e assim contribuir com esse campo de pesquisa da literatura. Ele se torna particularmente relevante em um momento em que a ANEEL busca expandir sua atuação como regulador por meio da implantação de novos dispositivos regulatórios que acompanhem a sustentabilidade econômico-financeira das distribuidoras de energia elétrica por meio da Consulta Pública 15/2014, que busca propostas a serem incorporadas na Nota Técnica n. 353/2014.

O setor elétrico, desde a década de 1990, vem passando por períodos de dificuldades financeiras em decorrência principalmente de interferências dos governos (SILVA, 2011). As distribuidoras de energia enfrentaram problemas financeiros na época em que o setor elétrico passou por várias privatizações juntamente com reformas regulatórias e também na época do racionamento de energia, ambos durante o governo de Fernando Henrique Cardoso (LANDI, 2006). Além disso, mais recentemente as distribuidoras precisaram ser socorridas pelo governo federal em virtude da inesperada descontratação de energia cativa, da advinda da MP $579 / 2012$, que foi promulgada durante o primeiro mandato do governo Dilma, juntamente com o coincidente período de forte estiagem das chuvas (COSTELLINI; HOLLANDA, 2014).

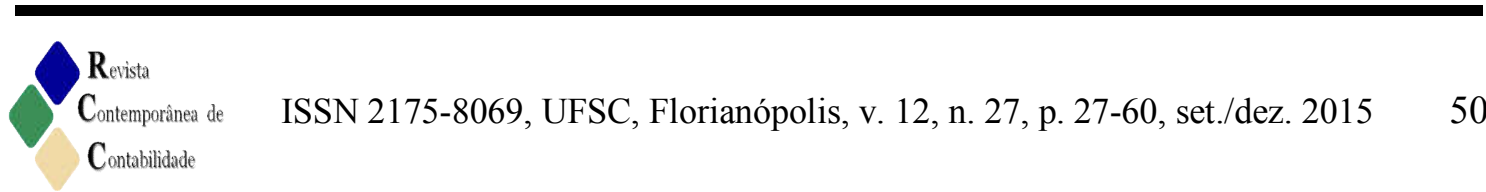


Devido à grande relevância que o setor elétrico possui, este trabalho visou contribuir com os interesses dos governos que historicamente tomam medidas que impactam o setor elétrico e, em contrapartida, contribuir com os interesses das empresas distribuidoras que são impactadas por essas medidas. Além disso, o trabalho contribui com os interesses da população que também depende dos serviços essenciais dessas empresas e se prejudica com a situação de insolvência empresarial.

Os resultados encontrados apresentaram consistência metodológica para as várias análises realizadas em diferentes amostras e períodos de tempo e demonstraram que as distribuidoras de energia elétrica tiveram indicadores relevantes para explicar a insolvência tanto no mesmo ano, quanto um ano e dois anos antes. O Indicador de Cobertura de Juros (ICJ) se mostrou como um bom discriminador entre as empresas solventes e insolventes para dois anos antes da ocorrência da insolvência e também para um ano antes, quando realizadas as análises de robustez dos modelos. Isso mostra que as empresas antes de se tornarem insolventes passaram por dificuldades com o pagamento de juros de dívidas por meio dos seus resultados operacionais.

Também foi constatado que um ano antes e no mesmo ano da insolvência, as empresas tinham dificuldades relacionadas com a Liquidez Geral, o que demonstra que a relação dos ativos totais com os passivos totais diminuiu. Também para o mesmo ano da insolvência, constatou-se que as distribuidoras apresentaram dificuldades operacionais, o que foi medido pelo indicador FEC/FECREG demonstrando que a frequência de interrupções de fornecimento de energia aumentou nas distribuidoras que se tornaram insolventes, o que pode ser ocasionado pelo menor nível de investimento e menor atenção das distribuidoras com as questões operacionais.

Por fim, este estudo trouxe contribuições significativas tanto à ANEEL em seu projeto de acompanhamento da sustentabilidade financeira e operacional das distribuidoras de energia elétrica por meio da Nota Técnica n. 353/2014, quanto para a literatura brasileira de performance financeira das empresas de energia elétrica. No que diz respeito às contribuições feitas para a ANEEL, conseguiu-se obter evidências de que as distribuidoras que se tornaram insolventes apresentaram antecipadamente, em dois anos antes, problemas na relação entre geração de lucros e pagamento de juros, representados por meio do indicador ICJ (RIBEIRO et al., 2012; STANDARD and POORS, 2013). Isso demonstra que esse deve ser um fator a ser monitorado com atenção pelo regulador, e que pode ser um dos indicadores a serem utilizados para fins de monitoramento da sustentabilidade das distribuidoras em conformidade com a Nota Técnica n. 353/2014, apesar de ele ainda não estar presente na proposta realizada até o momento.

Quando as empresas se encontraram em estado de insolvência, elas apresentaram problemas de liquidez representados pelo indicador Liquidez Geral (BRITO et al., 2009) e problemas operacionais medidos pelo indicador FEC/FECREG (ANEEL, 2014). Dessa forma, assim como o indicador ICJ, propõe-se que o indicador Liquidez Geral também passe a ser objeto de utilização da ANEEL.

Por sua vez, o indicador FEC/FECREG já é uma proposta da própria Nota Técnica $n$. $353 / 2014$, e foi constatado, por meio deste trabalho, que em termos operacionais o

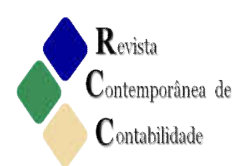


FEC/FECREG obteve melhor desempenho do que os indicadores DEC/DECREG (Duração Equivalente de Interrupção realizada/ Duração Equivalente de Interrupção regulatória) e IDGC (Indicador de Desempenho Global de Continuidade), que são os outros indicadores operacionais presentes na Nota Técnica e que também foram utilizados neste trabalho. Isso fornece evidências de que o FEC/FECREG pode ser um indicador mais relevante do que os demais e, portanto, deveria ser mais observado e demandar mais atenção por parte da ANEEL em relação aos demais indicadores.

Com relação à literatura, foram realizadas contribuições metodológicas em relação aos trabalhos existentes de Pereira et al. (2006), Ozório (2013), Bomfim et al. (2011) e Ribeiro et al. (2012), uma vez que, neste trabalho, foi utilizada a análise de regressão logística com uma amostra que abrangeu um período extenso de análise, levando em conta o período 1997 e 2014, enquanto os demais trabalhos se restringiam à análise de dados de curto prazo e, por vezes, à análise de dados de apenas um único ano (PEREIRA et al., 2006; BOMFIM et al., 2011). Além disso, este trabalho foi o único que fez uma análise de insolvência específica para as distribuidoras de energia elétrica brasileiras.

Assim como os demais trabalhos de insolvência da literatura, este trabalho possui limitações quanto à utilização de premissas para a definição de qual critério utilizar na identificação dessa situação nas empresas. Conforme Beaver et al. (2012), a insolvência poderia ser definida como a incapacidade de a empresa honrar com seus compromissos financeiros conforme eles vão chegando à maturidade. Para Dimitras et al. (1996), essa definição depende basicamente dos interesses específicos do pesquisador ou das condições das firmas que estiverem sob análise. De uma forma geral, ela poderia ser definida como a situação em que a empresa não pode pagar os credores, acionistas minoritários, fornecedores, etc., ou alternativamente, também poderia ser definida conforme legislações jurídicas. Além disso, ressalta-se que, neste trabalho, foi utilizada apenas uma técnica estatística de classificação, sendo ela a técnica de regressão logística sem a execução dos procedimentos de validação cruzada.

Para futuras pesquisas, podem ser feitas análises utilizando critérios de insolvência diferentes dos que foram utilizados neste estudo, como, por exemplo, reestruturações societárias, persistência de prejuízos a longo prazo, dentre outros, a exemplo da abordagem de Balcaen et al. (2011) e Balcaen et al. (2010). Sugere-se também que sejam feitas pesquisas com os dados da contabilidade regulatória instituída pela ANEEL a partir de 2010, que, apesar de haver uma disponibilidade de dados com período de tempo mais curto, teria maior quantidade de distribuidoras para ser objeto de análise. Além disso, outras metodologias poderiam ser adotadas para analisar o setor elétrico, a exemplo de diversas abordagens metodológicas presentes na literatura de insolvência (JACKSON; WOOD, 2013).

\section{Referências}

ALTMAN, E. I. Financial Ratios, Discriminant Analysis and the Prediction of Corporate Bankruptcy. The Journal of Finance, v. 23, n. 4, p. 589-609, 1968.

\footnotetext{
$\mathcal{C}_{\substack{\text { Contemporinea de } \\ \text { Contabilidade }}}^{R_{\text {evita }}}$ ISSN 2175-8069, UFSC, Florianópolis, v. 12, n. 27, p. 27-60, set./dez. 2015
} 
ALTMAN, E. I. The success of business failure prediction models. Journal of Banking \& Finance, v. 8, n. 2, p. 171-198, 1984.

ALTMAN, E. I.; BAIDYA, T. K. N.; DIAS, L. M. R. Previsão de problemas financeiros em empresas. Revista de Administração de Empresas, v. 19, n. 1, p. 17-28, 1979.

ALTMAN, E. I.; HALDEMAN, R. G.; NARAYANAN, P. ZETATM analysis A new model to identify bankruptcy risk of corporations. Journal of Banking \& Finance, v. 1, n. 1, p. 29$54,1977$.

ALTMAN, E. I.; SAUNDERS, A. Credit risk measurement: Developments over the last 20 years. Journal of Banking \& Finance, v. 21, n. 11-12, p. 1721-1742, 1997.

ANEEL. Nota Técnica nº 353/2014. 2014. SFF/ANEEL. Disponível em:

$<$ http://www.aneel.gov.br/aplicacoes/consulta_publica/documentos/NT_Indicadores $\% 20 \mathrm{de} \%$ 20Sustentabilidade.pdf $>$. Acesso em: 27/5/2015.

ASSAF NETO, A. Estrutura e Análise de Balanços: Um Enfoque Econômico Financeiro. 10. ed. São Paulo, SP: Atlas, 2012.

AZIZ, M. A.; DAR, H. A. Predicting corporate bankruptcy: where we stand? Corporate Governance: The international journal of business in society, v. 6, n. 1, p. 18-33, 2006.

BALCAEN, S.; BUYZE, J.; OOGHE, H. Financial Distress and Firm Exit: Determinants of Involuntary Exits, Voluntary Liquidations and Restructuring Exits. SSRN Scholarly Paper, Rochester, NY: Social Science Research Network, 2009.

BALCAEN, S.; MANIGART, S.; BUYZE, J.; OOGHE, H. Firm exit after distress: differentiating between bankruptcy, voluntary liquidation and M\&A. Small Business Economics, v. 39, n. 4, p. 949-975, 2011.

BALCAEN, S.; MANIGART, S.; OOGHE, H. From distress to exit: determinants of the time to exit. Journal of Evolutionary Economics, v. 21, n. 3, p. 407-446, 2010.

BALCAEN, S.; OOGHE, H. 35 years of studies on business failure: an overview of the classic statistical methodologies and their related problems. The British Accounting Review, v. 38, n. 1, p. 63-93, 2006.

BALL, R.; BROWN, P. An Empirical Evaluation of Accounting Income Numbers. Journal of Accounting Research, v. 6, n. 2, p. 159, 1968. 
BARROS, J. Aplicação De Modelos De Previsão De Insolvência Nas Operadoras De Planos De Saúde Do Brasil, 2013. Dissertação de Mestrado - Programa de Pós-Graduação em Administração, Vitória, ES: Fundação Instituto Capixaba de Pesquisa.

BEAVER, W. H. Financial Ratios As Predictors of Failure. Journal of Accounting Research, v. 4, p. 71, 1966.

BEAVER, W. H.; CORREIA, M.; MCNICHOLS, M. F. Do differences in financial reporting attributes impair the predictive ability of financial ratios for bankruptcy? Review of Accounting Studies, v. 17, n. 4, p. 969-1010, 2012.

BOMFIM, P. R. C. M.; ALMEIDA, R. S. DE; GOUVEIA, V. A. L.; MACEDO, M. A. DA S.; MARQUES, J. A. V. DA C. Utilização de Análise Multivariada na Avaliação do Desempenho Econômico-Financeiro de Curto Prazo: uma Aplicação no Setor de Distribuição de Energia Elétrica. Revista ADM.MADE, v. 15, n. 1, p. 75-92, 2011.

BRITO, G. A. S.; ASSAF NETO, A. A model for the classification of companies credit risk. Revista Contabilidade \& Finanças, v. 19, n. 46, p. 18-29, 2008.

BRITO, G. A. S.; ASSAF NETO, A.; CORRAR, L. J. Sistema de classificação de risco de crédito: uma aplicação a companhias abertas no Brasil. Revista Contabilidade \& Finanças, v. 20, n. 51, p. $28-43,2009$.

CARNEIRO, J. M. Modelo de previsão de insolvência de concessionárias de ferrovias no Brasil, 2011. Dissertação de Mestrado - Programa de Pós-Graduação em Engenharia Civil e Ambiental, Brasília: Universidade de Brasília.

CASTRO JUNIOR. Previsão de insolvência de empresas brasileiras usando análise discriminante, regressão logística e redes neurais, 2003. Dissertação de Mestrado Programa de Pós-Graduação em Administração, São Paulo, SP: Universidade de São Paulo.

CATAPAN, E. A. A privatização do setor elétrico brasileiro: os reflexos na rentabilidade e solvência das empresas distribuidoras de energia, 2005. Tese de Doutorado - Programa de Pós-Graduação em Engenharia de Produção, Santa Catarina: Universidade Federal de Santa Catarina.

COSTELLINI, C.; HOLLANDA, L. SETOR ELÉTRICO: DA MP 579 AO PACOTE FINANCEIRO. Disponível em: $<$ http://fgvenergia.fgv.br/artigos/setor-eletrico-da-mp-579-aopacote-financeiro $>$. Acesso em: 22/5/2015.

CROUHY, M.; GALAI, D.; MARK, R. A comparative analysis of current credit risk models. Journal of Banking \& Finance, v. 24, n. 1-2, p. 59-117, 2000. 
DELEN, D.; KUZEY, C.; UYAR, A. Measuring firm performance using financial ratios: A decision tree approach. Expert Systems with Applications, v. 40, n. 10, p. 3970-3983, 2013.

DIMITRAS, A. I.; ZANAKIS, S. H.; ZOPOUNIDIS, C. A survey of business failures with an emphasis on prediction methods and industrial applications. European Journal of Operational Research, v. 90, n. 3, p. 487-513, 1996.

ELISABETSKY, R. Um modelo matemático para decisão de crédito no Banco Comercial, 1976. São Paulo, SP: Escola Politécnica da Universidade de São Paulo.

FÁVERO, L. P. Modelos de Regressão com Excel®, Stata ${ }^{\circledR}$ e SPSS®. 1. ed. Rio de Janeiro, RJ: Elsevier, 2015.

FÁVERO, L. P.; BELFIORE, P.; DA SILVA, F.; CHAN, B. L. Análise de Dados: Modelagem Multivariada para Tomada de Decisões. 1. ed. Rio de Janeiro, RJ: Elsevier, 2009.

GOMES, J. P. P.; VIEIRA, M. M. F. The electricity sector in Brazil from 1880 through 2002. Revista de Administração Pública, v. 43, n. 2, p. 295-321, 2009.

GORDY, M. B. A comparative anatomy of credit risk models. Journal of Banking \& Finance, v. 24, n. 1-2, p. 119-149, 2000.

GUIMARÃES, A.; MOREIRA, T. B. S. Previsão de insolvência: um modelo baseado em índices contábeis com utilização da análise discriminante. Revista de Economia Contemporânea, v. 12, n. 1, p. 151-178, 2008.

HAIR, J. F.; BLACK, W. C.; BABIN, B. J.; ANDERSON, R. E. Multivariate data analysis. 7. ed. Upper Saddle River, NJ: Prentice Hall, 2010.

JACKSON, R. H. G.; WOOD, A. The performance of insolvency prediction and credit risk models in the UK: A comparative study. The British Accounting Review, v. 45, n. 3, p. 183-202, 2013.

KANITZ, S. Como prever falências. São Paulo, SP: McGraw-Hill, 1978.

LANDI, M. Energia elétrica e políticas públicas: a experiência do setor elétrico brasileiro no período de 1934 a 2005, 2006. Tese de Doutorado - Programa de Pós-Graduação em Energia, São Paulo, SP: Universidade de São Paulo.

LIN, F.; LIANG, D.; CHEN, E. Financial ratio selection for business crisis prediction. Expert Systems with Applications, v. 38, n. 12, p. 15094-15102, 2011. 
LOPEZ, J. A.; SAIDENBERG, M. R. Evaluating credit risk models. Journal of Banking \& Finance, v. 24, n. 1-2, p. 151-165, 2000.

MARICICA, M.; GEORGETA, V. Business Failure Risk Analysis using Financial Ratios. Procedia - Social and Behavioral Sciences, v. 62, p. 728-732, 2012.

MÁRIO, P. DO C. Contribuição ao estudo da solvência empresarial: uma análise de modelos de previsão - estudo exploratório aplicado em empresas mineiras, 2002.

Dissertação de Mestrado - Programa de Pós-Graduação em Controladoria e Contabilidade, São Paulo, SP: Universidade de São Paulo.

MARTINS, M. S. A previsão de insolvência pelo modelo de Cox : uma contribuição para a análise de companhias abertas brasileiras, 2003. Dissertação de Mestrado - Programa de Pós-Graduação em Administração, Porto Alegre, RS: Universidade Federal do Rio Grande do Sul.

MATIAS, A. B. Indicadores contábeis e financeiros de previsão de insolvência: a experiência da pequena e média empresa, 1976. Tese de Livre Docência, São Paulo, SP: Faculdade de Economia, Administração e Contabilidade da Universidade de São Paulo.

MEARS, P. K. Discussion of Financial Ratios As Predictors of Failure. Journal of Accounting Research, v. 4, p. 119, 1966.

NASCIMENTO, S.; PEREIRA, A. M.; HOELTGEBAUM, M. Aplicação dos Modelos de Previsão de Insolvências nas Grandes Empresas Aéreas Brasileiras. Revista de Contabilidade do Mestrado em Ciências Contábeis da UERJ, v. 15, n. 1, p. 40-51, 2011.

NETER, J. Discussion of Financial Ratios as Predictors of Failure. Journal of Accounting Research, v. 4, p. 112, 1966.

NIEMANN, M.; SCHMIDT, J. H.; NEUKIRCHEN, M. Improving performance of corporate rating prediction models by reducing financial ratio heterogeneity. Journal of Banking \& Finance, v. 32, n. 3, p. 434-446, 2008.

OBERMANN, L.; WAACK, S. Demonstrating non-inferiority of easy interpretable methods for insolvency prediction. Expert Systems with Applications, v. 42, n. 23, p. 9117-9128, 2015.

OHLSON, J. A. Financial Ratios and the Probabilistic Prediction of Bankruptcy. Journal of Accounting Research, v. 18, n. 1, p. 109-131, 1980. 
OZÓRIO, L. de M. Análise do Desempenho Econômico-Financeiro de Distribuidoras de Energia Elétrica no Brasil, 2013. Tese de Pós-Doutorado, Rio de Janeiro, RJ: Universidade Federal do Rio de Janeiro.

PEREIRA, A. F.; PEDROSA, C.; SANTOS RAMOS, E. J. Modelo e Análise de Previsão de Desempenho pela Metodologia de Análise Multivariada de Dados: um estudo empírico do setor de energia elétrica. Revista Contemporânea de Contabilidade, v. 3, n. 5, p. 59-74, 2006.

PINHEIRO, L. E. T.; PINHEIRO, J. L. Modelos de Evaluación del Riesgo de Insolvencia de Empresas Españolas Cotizadas. Contabilidade Vista \& Revista, v. 19, n. 3, p. 95-121, 2009.

RIBEIRO, M. G. C.; MACEDO, M. A. DA S.; MARQUES, J. A. V. DA C. Análise da relevância de indicadores financeiros e não financeiros na avaliação de desempenho organizacional: um estudo exploratório no setor brasileiro de distribuição de energia elétrica. Revista de Contabilidade e Organizações, v. 6, n. 15, p. 60-79, 2012.

RIO BRAVO. Para entender a MP 579. Rio Bravo, 2012.

SANVICENTE, A.; MINARDI, A. M. A. F. Identificação de indicadores contábeis significativos para previsão de concordata de empresas. Finance Lab Working Papers, Ibmec Business School São Paulo., 1998. Disponível em:

$<$ http://www.risktech.com.br/PDFs/indicadores_concordata.pdf $>$. Acesso em: 3/5/2015.

SILVA, B. G. Evolução do setor elétrico brasileiro no contexto econômico nacional: uma análise histórica e econométrica de longo prazo, 2011. Dissertação de Mestrado - Programa de Pós-Graduação em Energia, São Paulo, SP: Universidade de São Paulo.

SILVA, J. O.; WIENHAGE, P.; SOUZA, R. P. S. DE; BEZERRA, F. A.; LYRA, R. L. W. C. DE. Capacidade Preditiva de Modelos de Insolvência com Base em Números Contábeis e Dados Descritivos. Revista de Educação e Pesquisa em Contabilidade (REPeC), v. 6, n. 3, 2012.

SOARES, R. A.; REBOUÇAS, S. M. D. Avaliação do Desempenho de Técnicas de Classificação Aplicadas à Previsão de Insolvência de Empresas de Capital Aberto Brasileiras. Revista ADM.MADE, v. 18, n. 3, p. 21, 2014.

STANDARD AND POORS. Metodologia Corporativa: Índices e Ajustes. 2013.

TAMARI, M. Financial Ratios as a Means of Forecasting Bankruptcy. Management International Review, v. 6, n. 4, p. 15-21, 1966. 
VIRGILLITO, S. B.; FAMÁ, R. A Análise Estatística Multivariada na Previsão de Insolvência de Empresas. Revista Administração em Diálogo, v. 4, n. 1, 2008.

WANG, Y.; LEE, H. A clustering method to identify representative financial ratios. Information Sciences, v. 178, n. 4, p. 1087-1097, 2008.

WATTS, R. L.; ZIMMERMAN, J. L. Towards a Positive Theory of the Determination of Accounting Standards. The Accounting Review, v. 53, n. 1, p. 112, 1978.

WATTS, R. L.; ZIMMERMAN, J. L. Positive Accounting Theory: A Ten Year Perspective. The Accounting Review, v. 65, n. 1, p. 26, 1990.

WOOLDRIDGE, J. M. Introdução à econometria: uma abordagem moderna. 4. ed. Brasil: Censage Learning, 2011.

WRUCK, K. H. Financial distress, reorganization, and organizational efficiency. Journal of Financial Economics, v. 27, n. 2, p. 419-444, 1990. 


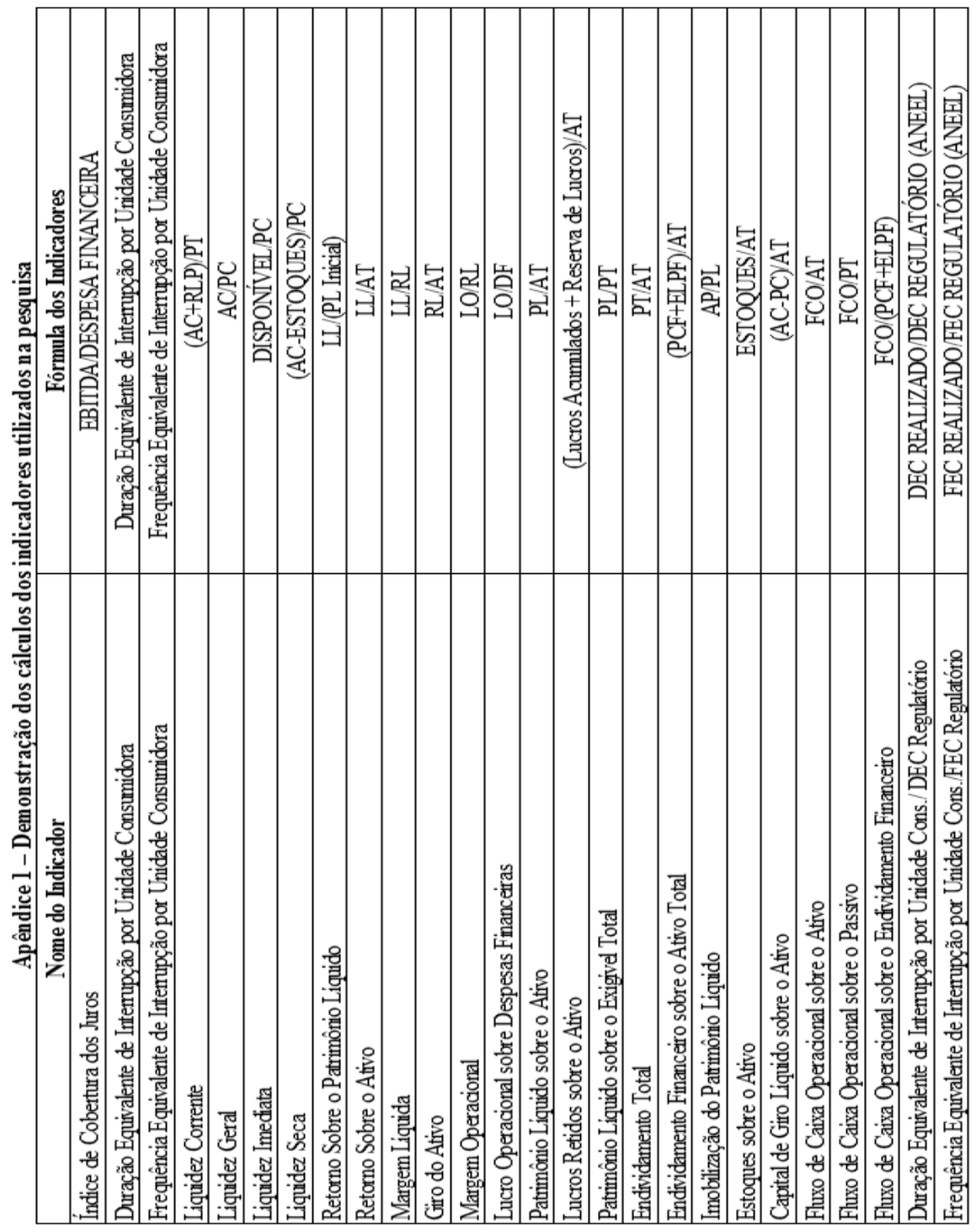

59 ISSN 2175-8069, UFSC, Florianópolis, v. 12, n. 27, p. 27-60, set./dez. 2015

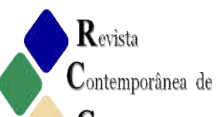



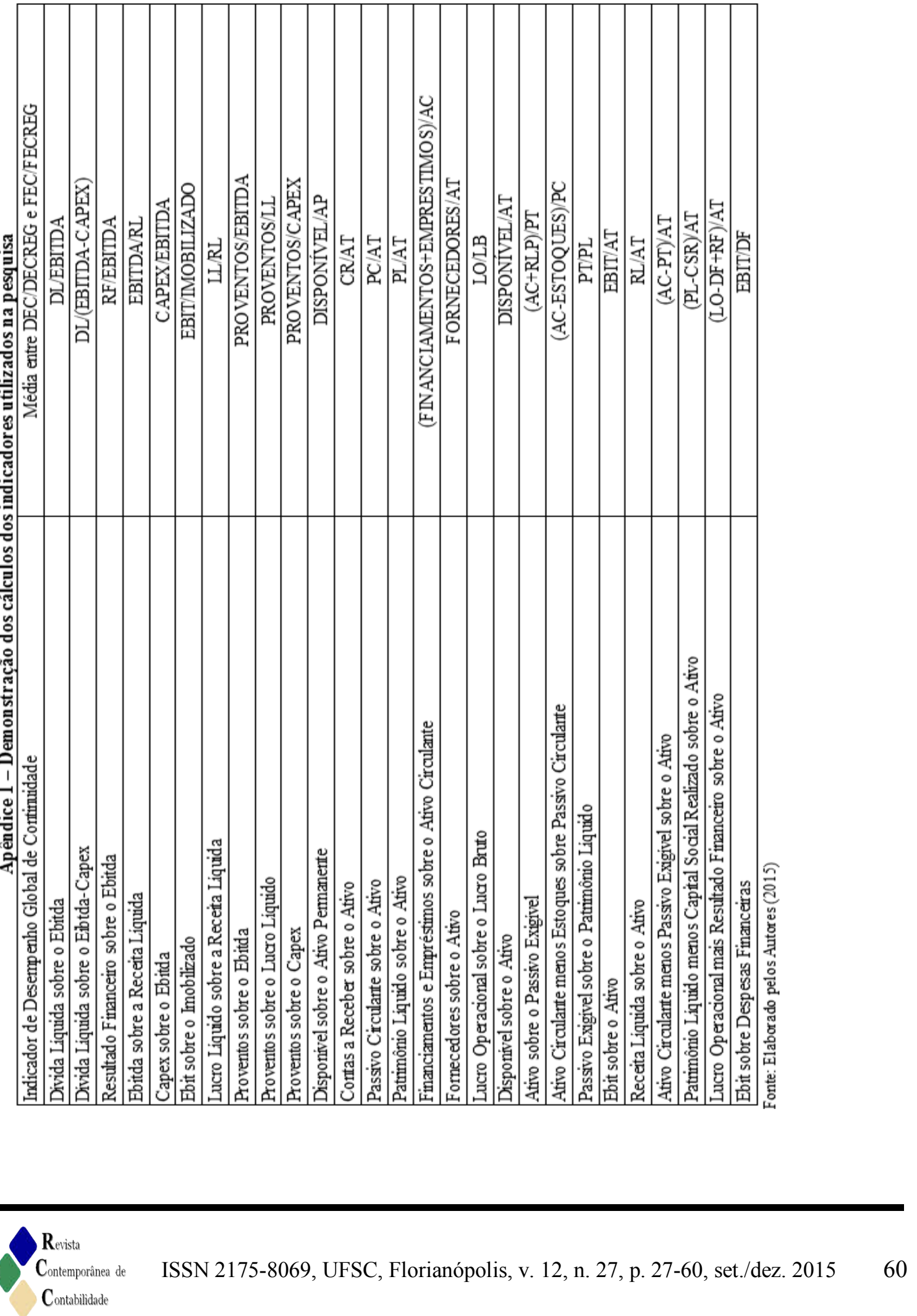